\title{
The multiple functions of gingival and mucoperiosteal fibroblasts in oral wound healing and repair
}

\author{
Matthias Chiquet ${ }^{1}$, Christos Katsaros ${ }^{1}$, and Dimitris Kletsas ${ }^{2}$ \\ Periodontol 2000. 2015 Jun;68(1):21-40. doi: 10.1111/prd.12076.
}

Accepted Manuscript; Contributor's version

The final version is available from http://onlinelibrary.wiley.com/ 


\title{
The multiple functions of gingival and mucoperiosteal fibroblasts in oral wound healing and repair
}

\author{
Matthias Chiquet ${ }^{1}$, Christos Katsaros ${ }^{1}$, and Dimitris Kletsas ${ }^{2}$ \\ ${ }^{1}$ Department of Orthodontics and Dentofacial Orthopedics, Dental School, University of \\ Bern, Bern, Switzerland \\ 'Laboratory of Cell Proliferation and Ageing, Institute of Biology, NCSR "Demokritos", \\ Athens, Greece
}

\section{Correspondence:}

Professor Matthias Chiquet, Ph.D.

Department of Orthodontics and Dentofacial Orthopedics

School of Dental Medicine / Medical Faculty, University of Bern

Freiburgstrasse 7

$\mathrm{CH}-3010$ Bern, Switzerland

Phone: $\quad+41-31-632-9882$

Fax: $\quad+41-31-632-9869$

e-Mail: matthias.chiquet@zmk.unibe.ch

Running title:

Fibroblasts in oral wound healing

\section{Monograph title:}

Wound healing in Periodontology and Implantology

Guest Editors: Anton Sculean, lain Chapple 


\begin{abstract}
Fibroblasts are cells of mesenchymal origin responsible for the production of most extracellular matrix in connective tissues, and are essential for wound healing and repair. In recent years, it has become clear that fibroblasts from different tissues are distinct in various traits. Moreover, wounds in the oral cavity heal under very special environmental conditions compared to e.g. skin wounds. Here, we reviewed the current literature on the various interconnected functions of gingival and mucoperiosteal fibroblasts during the repair of oral wounds. The Medline database was searched with the following terms: (gingival OR mucoperiosteal) AND fibroblast AND (wound healing OR repair). The gathered data was used to compare oral fibroblasts to those from other tissues in terms of their regulation and function during wound healing. Specifically, we sought answers to the following questions: a) what is the role of oral fibroblasts in the inflammatory response in acute wounds, b) how do growth factors control the function of oral fibroblasts during wound healing, c) how do oral fibroblasts produce, remodel and interact with extracellular matrix in healing wounds, d) how do oral fibroblasts respond to mechanical stress, and e) how does aging affect the fetal-like responses and functions of oral fibroblasts? The current state of research indicates that oral fibroblasts possess unique characteristics and tightly controlled specific functions in wound healing and repair. This information is essential for developing new strategies to control the intraoral wound healing processes of the individual patient.
\end{abstract}


Fibroblasts are cells of mesenchmal origin; they are responsible for the production of most of the extracellular matrix of interstitial connective tissue, and essential for the process of wound healing and repair. Most of what is known about the functions of this cell type stems from work on embryonic dermal fibroblasts and cell lines derived from them. However, there is increasing evidence that fibroblasts from different tissue origins are distinct in terms of their gene expression profile, growth characteristics, motility, and other traits $(42,67,112$, $113,124)$. Gingival and mucoperiosteal fibroblasts (like other fibroblasts in the head) are special in that they are generated from neural crest derived "ectomesenchyme" during development, not from the primary mesoderm like most other fibroblasts in the body. Moreover, they are associated with a (entodermal) mucosal epithelium, not with (ectodermal) epidermis like e.g. dermal fibroblasts. Although gingival and mucoperiosteal fibroblasts have much in common with other fibroblastic cells, from their specific developmental origin and location it is to be expected that they respond distinctly to the challenge of a wound, allowing them to cope optimally with the special conditions in the oral cavity. This article critically reviews the corresponding evidence.

A systematic literature survey was performed by searching the Medline database with the following terms: (gingival OR mucoperiosteal) AND fibroblast AND (wound healing OR repair). The term "periodontal ligament fibroblast" was not included, since this review focuses on wound healing of the gingiva and oral mucosa rather than on periodontal repair. However, since many cited articles compare gingival with periodontal ligament fibroblasts in wound healing models, the specific charateristics of periodontal fibroblasts are also covered to some extent. The above search yielded 314 publications (as of August 4, 2011). In a first screening of all abstracts, 100 references were excluded for the following reasons:

- No abstract available in Medline;

- Language other than English;

- Case studies involving a single patient;

- Publications in which the term "fibroblast" appeared in the key words but neither in the title nor in the abstract;

- Studies in which fibroblasts were only imaged and/or counted cytologically, without further insight into their role in the wound healing process investigated;

- Studies where fibroblasts only served as controls (or feeder cells) for other cell types.

Of the remaining 214 articles, roughly half were considered of high relevance and good data quality, and these are covered in detail here. Results from selected further relevant publications were added after searching the reference lists of cited articles. 
The gathered information was used to ask the following general question: How similar or dissimilar are oral fibroblasts to those from other tissues in terms of their regulation and function during wound healing? Specific sub-questions are addressed in the following paragraphs.

\section{The role of oral fibroblasts in the inflammatory response in acute wounds}

The most prominent and essential function of fibroblasts in wound healing is of course the production of new extracellular matrix for repairing damaged tissue. However, it is important to realize that resident fibroblasts in healthy connective tissues are "sleeper" cells with a very low mitotic and biosynthetic activity. To produce large amounts of new extracellular matrix, they need to be "activated", which implies that they must be able to sense and respond to a plethora of external stimuli. This second, very important role of fibroblasts as "sentinel" cells (131) that monitor connective tissue homeostasis has been recognized only in the last two decades. Fibroblasts, the dominant population of resident cells in many tissues, respond to the very first signs of tissue damage and bacterial infection (Fig. 1). In an acute wound, where blood leaks into the interstitial tissue, growth factors and chemokines released by degranulating blood platelets not only attract immune cells, but also directly stimulate resident fibroblasts to produce and secrete additional chemokines, most notably interleukin6 and interleukin-8, which recruit neutrophils to the site of damage (94). In case of infection, lipopolysaccharide and other bacterial products again induce production of interleukin-6, -8, and other chemokines by fibroblasts (13). A complex crosstalk between resident fibroblasts and invading immune cells ensues and controls the course of the inflammation and tissue repair. Direct cell-to-cell contacts are formed between CD40 (a member of the tumor necrosis factor- $\alpha$ receptor superfamily) on the surface of resident fibroblasts and its ligand CD40-L on invading immune cells (125). These contacts lead to additional mutual activation of both cell types: as a result, fibroblasts secrete more chemokines and immune cells release inflammatory cytokines, leading to amplification of the response to injury (Fig. 1).

Fibroblasts in an acute wound immediately respond to factors released by activated platelets. Among these are growth factors like platelet-derived growth factor-BB or transforming growth factor- $\beta$, small mediators like lysophosphatidic acid, proteases like urokinase-type plasminogen activator, and chemokines like platelet factor-4 (104). Plateletderived growth factor is a potent mitogen for fibroblasts by activating mitogen-activated protein kinase and phosphatidylinositol 3-kinase pathways via platelet-derived growth factor -receptor, a membrane-bound receptor tyrosine kinase (147). Moreover, platelet-derived growth factor stimulates orbital fibroblast migration and induces the expression and 
secrection of interleukin-8; presumably via different signaling pathways (152). In addition to attracting immune cells by chemokine secretion, another primary task of fibroblasts in the repair process is contraction of the wound's margins in order to accelerate its closure. This process is again triggered by platelet- and plasma-derived factors such as lysophosphatidic acid and thrombin. Wound contraction in vivo can be modeled in vitro by seeding fibroblasts into a fibrillar collagen gel, which in the presence of serum is contracted by the cells within 12 days. Lysophosphatidic acid acts on fibroblasts via a G-protein coupled receptor and can trigger multiple intracellular signaling pathways, most notably a rapid activation of the small GTPase RhoA and its target Rho-dependent kinase ROCK, which stimulate actin assembly and contractility and hence initiate wound contraction (96). A popular way to study certain aspects of wound healing in vitro is the so-called "scratch" or "wound fill" assay, where a scratch of defined dimensions is inflicted on a fibroblast monolayer in a cell culture dish, and the closure of the wound is observed, which occurs as a consequence of fibroblast proliferation and migration. Using this assay, it has been shown that lysophosphatidic acid on its own does not significantly stimulate wound fill by gingival fibroblasts; however, it acts synergistcally with the potent mitogen platelet-derived growth factor-BB, and the combination of these two platelet mediators is as potent as $10 \%$ serum in stimulating gingival fibroblasts to close a wound in vitro (16). Very similar results were obtained for periodontal ligament fibroblasts, for which it was also shown that they express LPAR-1, -2 and -3 , the G-proteincoupled cell surface receptors for lysophosphatidic acid (17). Using receptor-specific agonists, the same authors further demonstrated that all three LPAR subtypes activate the mitogen-activated protein kinase ERK-1/2 in both gingival and periodontal ligament fibroblasts, whereas intracellular $\mathrm{Ca}^{2+}$ mobilization is triggered by LPAR-1 and -3 but not -2 . In gingival fibroblasts, a chemotactic response to lysophosphatidic acid was mediated primarily through LPAR-1; in periodontal ligament fibroblasts, the other receptor subtypes were involved as well, pointing to origin-specific differences in the response of fibroblasts to lysophosphatidic acid (45). Other factors released by platelets are involved in the activation of plasma-derived prothrombin to thrombin (104). In an acute wound, the protease thrombin is required for fibrin clot formation, but much like platelet-derived growth factor it also works as a bona fide growth factor, by interacting with a cell surface receptor called proteaseactivated receptor that is also found on fibroblasts (Fig. 1). Like platelet-derived growth factor, thrombin can trigger mitogen-activated protein kinase and RhoA/ROCK signaling pathways, among others (77). Thrombin was found to stimulate the growth of human gingival fibroblasts in vitro, as well as to induce the rapid contraction of collagen lattices by these cells (19). Interestingly, fibroblast proliferation but not collagen gel contraction was inhibited 
by a thrombin-specific protease inhibitor. Thrombin-induced fibroblast contraction was abolished by the actin-depolymerizing drug cytochalasin B (19) and by ROCK inhibition (69), and hence appears to depend on an intact, contractile actin cytoskeleton. In a more recent paper by the same authors, it was shown that gingival and mucosal fibroblasts express the thrombin receptors, protease activated receptor -1 and -3 , and that thrombin rapidly triggers signaling by small GTPase Ras, p38 mitogen activated kinase, and c-AMP responsive transcription factor CREB/ATF-1. As a consequence, early response genes are activated like those for transcription factors $c$-fos, $c$-jun and c-myc, which are required for the induction of secondary genes involved in fibroblast proliferation and differentiation (18). Another group used pharmacological inhibitors to probe the signaling pathway responsible for collagen lattice contraction by gingival fibroblasts (69). They concluded that this process is mediated mainly by thrombin binding to protease activated receptor-1, activation of phospholipase $\mathrm{C}$, extracellular $\mathrm{Ca}^{2+}$ influx through L-type channels, and triggering of the calcium/calmodulinmyosin light chain kinase and RhoA/ROCK pathways that finally stimulate actomyosin contraction.

Especially in the oral cavity, every damage to the tissue is immediately accompanied by bacterial infection, and oral fibroblasts respond rapidly and strongly to bacterial products such as lipopolysaccharide from cell walls (Fig. 1). An early response of gingival fibroblasts to lipopolysaccharide involves increased synthesis of hyaluronic acid (6), an extracellular matrix glycosaminoglycan known to increase cell motility (101). The rise in hyaluronic acid seems to be mediated by lipopolysaccharide-dependent induction of prostaglandin-E2 synthesis by the fibroblasts since it is blocked by the anti-inflammatory drug indomethacin, an inhibitor of cyclooxygenases and thus prostaglandin production (6). Lipopolysaccharide at high concentrations $(50 \mu \mathrm{g} / \mathrm{ml})$ effectively inhibits the proliferation of gingival fibroblasts (presumably contributing to the compromised wound healing in periodontitis), but this inhibition can be partially overcome by platelet-derived growth factor (7). In contrast, low concentrations of lipopolysaccharide $(<9 \mu \mathrm{g} / \mathrm{ml})$ are slightly stimulatory for gingival fibroblast proliferation and seem to synergistically enhance the mitogenic action of interleukin-1 $\alpha$ and growth factors (59), which are secreted by immune cells upon inflammation. Thus it seems that lipopolysaccharide concentration, i.e. distance from the site of infection, differentially modulates the action of inflammatory cytokines and growth factors on gingival fibroblasts. In both healthy gingival fibroblasts and those isolated from periodontitis patients, lipopolysaccharide and interleukin-1 $\alpha$ induce interleukin- 6 production in an additive manner, but fibroblasts from inflamed gingiva constitutively produce more interleukin- 6 than their counterparts from healthy individuals. (72). 
Once oral fibroblasts have attracted immune cells to the site of the early wound by chemokine secretion, they amplify the response by in turn reacting strongly to the inflammatory cytokines released by these cells, as well as by interacting directly with them. CD40 (a member of the tumor necrosis factor- $\alpha$ receptor family) is known as an important receptor on B-lymphocytes regulating their proliferation and differentiation. Resting fibroblasts express low levels of this protein, but interestingly CD40 has been found to be upregulated 10 -fold by the inflammatory cytokine interferon- $\gamma$, and may facilitate inflammation by interacting with CD40-ligand on the surface of T-lymphocytes and mast cells. Interferon-y also shifts fibroblasts to the G0/G1-phase of the cell cycle, and it appears that high CD40 expression by fibroblasts is coupled to the cell cycle (43). Interleukin-1 $\beta$ and tumor necrosis factor- $\alpha$ stimulate the synthesis of prostaglandins and arachidonic acid by gingival fibroblasts; this effect is synergistically enhanced by epidermal growth factor, which boosts expression and/or activity of cyclooxygenase, a key enzyme in prostaglandin synthesis (95). Certain chemokines expressed by gingival fibroblasts are negatively regulated by inflammation, however. Stromal-derived factor-1 is a chemokine of the CXC family that is constitutively expressed by fibroblasts in most tissues and thought to be required for the homeostasis of healthy connective tissues. Stromal-derived factor-1 expression by gingival fibroblasts was found to be potently inhibited by activated macrophages via their secretion of interleukin-1 $\alpha$ and tumor necrosis factor- $\alpha$ (40). In addition to regulating the synthesis and release of many factors in fibroblasts, immune cellderived inflammatory cytokines also affect their motility. A direct target of interleukin-1 on fibroblasts appears to be focal adhesions, i.e. sites of cellular attachment to the extracellular matrix. Interestingly, the majority of interleukin-1 receptors on fibroblasts localize to focal adhesions together with integrins. Treatment of cultured fibroblasts with interleukin-1 leads to rapid phosphorylation of the integrin-associated protein talin, causing an increased turnover of focal adhesions (115). This action of interleukin-1 presumably stimulates fibroblast motility at early stages of inflammation. In gingival fibroblasts, interleukin- $1 \alpha / \beta$ and tumor necrosis factor- $\alpha$ additionally induce the rapid transcription and secretion of hepatocyte growth factor (also called scatter factor) (141), which within minutes stimulates cell motility via it cellular receptor c-Met (148). Another publication claims that hepatocyte growth factor is upregulated indirectly in oral fibroblasts, namely through the autocrine action of prostaglandin-E2, which is induced by inflammatory cytokines and bacterial components (106).

The mutual exchange of information between oral fibroblasts and immune cells during the inflammatory process finally results in the "activated" fibroblast phenotype typical for wound granulation tissue, which clearly differs from their normal "resting" state (Fig. 1). 
For example, granulation-tissue fibroblasts from periodontal lesions differ from normal gingival fibroblasts in their cloning capabilities in vitro: their cloning efficiency is lower (i.e. a smaller proportion of individual cells grows to clones), and their proliferative capacity decreases more rapidly than that of normal gingival fiboblasts (55). Gingival fibroblasts from sites of periodontitis have reduced levels of enzymes involved in DNA repair and therefore seem to be compromised in this vital activity (46). On the other hand, granulation-tissue fibroblasts are clearly differentiated cells in the sense that a high proportion of them expresses $\alpha$-smooth muscle actin, which is typical for contractile cells. Moreover, compared with fibroblasts form normal gingiva, those from granulation-tissue show higher basal expression levels for several extracellular matrix proteins, and they respond to transforming growth factor- $\beta$ by generating a larger increase in extracellular matrix production (56). In general, the exposure to inflammatory cytokines changes the pattern of extracellular matrix expression by granulation tissue fibroblasts. For example, interleukin-4 induces synthesis and secretion of various proteoglycans by gingival fibroblasts (58); due to the osmotic activity of the acidic side chains of proteoglycans, this is likely to increase the water content of inflamed tissue. During oral wound healing, the extracellular matrix of the granulation tissue is continously remodeled by matrix metalloproteinases, most notably the major gelatinases, matrix metalloproteinase- 2 and -9 . Whereas matrix metalloproteinase- 2 is constitutively expressed by mucosal fibroblasts and minimally affected by growth factors and cytokines, matrix metalloproteinase- 9 is rapidly induced after wounding in the granulation tissue (122).

It is important to note that fibroblasts are the direct targets of many intrinsic compounds as well as external stimuli and drugs that modulate the inflammatory process and hence fibroblast activation (132). Since many drugs are taken orally, oral fibroblasts are especially exposed. For example, a well-studied side effect of the anti-hypertensive drug nifedipine is gingival overgrowth. This might be caused by gingival fibroblasts secreting increased amounts of keratinocyte growth factor (a member of the fibroblast growth factor family also called FGF-7), which is induced by the drug at the mRNA and protein level (33, 34). Similarly, diphenylhydantoin is an antiepileptic drug with several side effects; one of which is again gingival overgrowth. It seems that diphenylhydantoin increases primary inflammation, infiltration of the wound by fibroblasts, and angiogenesis, finally leading to overgrowth (30). Conversely, the glucocorticoid drug dexamethasone, with its wellestablished anti-inflammatory action, decreases the expression of mRNAs for matrix metalloproteinases- 1 and -2 as well as for tissue inhibitors of metalloproteinases (TIMP)-1 and -2 in gingival and periodontal ligament fibroblasts (80). Another external stimulus reducing inflammation is low-energy irradiation with a He-Ne-laser, which has been reported to inhibit the expression of interleukin- $1 \beta$ and interferon- $\gamma$ and to induce platelet-derived 
growth factor and transforming growth factor- $\beta$ in gingival/mucosal wounds in the rat (120). Thus, low doses of red light might suppress inflammation and accelerate wound healing in the oral cavity. Another study has looked at the mode of action by which irradiation with red (635 nm) LED light inhibits the response to inflammatory mediators in gingival fibroblasts. It was found that, similar to nonsteroidal anti-inflammatory drugs, red light irradiation inhibited the expression of cyclooxygenase and the release of prostaglandin-E2 by gingival fibroblasts treated with arachidonic acid (85). Unlike indomethacin or ibuprofen, however, irradiation of gingival fibroblasts with red light also lead to a decrease in reactive oxygen species levels and in the mRNA for phospholipase A2 (85). The authors suggest that red light acts by directly dissociating reactive oxygen species, which consequently leads to a suppression of the other inflammatory responses. Interestingly, mechanical stimulation of periodontal tissue with a powered toothbrush has also been shown to decrease leukocyte infiltration and to incease the number of gingival fibroblasts in lipopolysaccharide-induced periodontal disease; the treatment might thus accelerate the healing of gingival inflammation (37). By contrast, blue light can also inhibit the proliferation of human gingival fibroblasts, while high doses can even lead to apoptosis $(64,142)$.

As for intrinsic factors, sex hormones are known to influence the response of various tissues to an immune challenge, and this has been investigated for gingival fibroblasts as well. In a transcript profiling study, it was found that the inflammatory cytokine interleukin-1 $\beta$ induced the expression of numerous chemokines in gingival fibroblasts, whereas induction of most of these genes was suppressed by adding progestin together with interleukin-1 $\beta$ (82). For interleukin-8 and monocyte chemotactic protein-1, these findings were confirmed on the protein level by measuring secreted chemokines by ELISA (82). Thymosin- $\beta 4$ is an ubiquitous protein with anti-inflammatory and anti-apoptotic action. Interestingly, thymosin$\beta 4$ was found to inhibit the induction of interleukin- 8 in gingival fibroblasts by tumor necrosis factor- $\alpha$, but not by lysophosphatidic acid (119). Finally, antimicrobial peptides like LL-37 or histatins are small components secreted by the salivary glands, with multiple functions in innate immunity and wound repair in the oral cavity (31). One study compared the effects of histatin-2 and LL-37 on early responses of fibroblasts during inflammation and wound healing (110). Histatin-2 was found to enhance fibroblast migration; however, it had little effect on their proliferation, and it did not alter their interleukin-8 synthesis or lipopolysaccharide-induced chemokine expression. In contrast, LL-37 stimulated both migration and proliferation of fibroblasts at $1 \mu \mathrm{M}$ but was cytotoxic at higher concentrations. Furthermore, LL-37 induced interleukin-8 expression but attenuated lipopolysaccharidedependent chemokine production (110). Thus, it seems that antimicrobial peptides in the saliva function as modulators of fibroblast activity during oral wound repair. 
Finally, it might be of increasing diagnostic and clinical relevance that components secreted by activated fibroblasts accumulate in crevicular fluid and can be measured there. Using antibody arrays, it was reported that interleukin-8 and transforming growth factor- $\beta 2$ are present at high concentrations in crevicular fluid of both healthy an diseased subjects. Among others, the cyto- and chemokines tumor necrosis factor- $\beta$, interleukin-16 and GRO, the growth factors epidermal growth factor, fibroblast growth factor-4 and vascular endothelial growth factor, the metalloproteinase inhibitor TIMP-2, and osteoprotegerin (an inhibitor of osteoclast activation) were found to be significantly enhanced in crevicular fluid of periodontitis patients (121). Thus for monitoring periodontal disease and wound healing, crevicular fluid seems to be an easily accessible and useful source, on which antibodies to relevant cytokines and growth factors can be used as diagnostic tools.

\section{Growth factor-mediated control of fibroblast function during oral wound healing}

Immediately after wound formation, activated platelets and other immunocytes, as well as adjacent cell types, secrete a large number of growth factors into the wounded area, e.g. platelet-derived growth factor, transforming growth factor- $\beta$, insulin-like growth factor-I and II, basic fibroblast growth factor and epidermal growth factor. These factors regulate crucial functions such as the migration, proliferation and contraction of several cell types, of which the most important in granulation tissues are fibroblasts (91).

Migration of fibroblasts into the injured area represents an immediate tissue response to injury, as these cells can populate this region and secrete extracellular matrix components towards healing. Early studies have shown that many of the growth factors mentioned above (platelet-derived growth factor, transforming growth factor- $\beta$, insulin-like growth factor, epidermal growth factor) can stimulate the migration of human gingival fibroblasts in a dose-dependent manner (103). Mechanistic studies on these actions are rather limited. Concerning platelet-derived growth factor, it has been shown that its migratory action is mediated through the p38-mitogen activated protein kinase signal transduction pathway (117). In addition, platelet-derived growth factor stimulates also the migration of gingival fibroblasts on titanium surfaces, which was correlated with release of urokinase-type plasminogen activator (2).

Growth factors are also potent inducers of cell proliferation; however their action is cell type specific. In vitro studies have shown that gingival fibroblasts are stimulated towards proliferation by platelet-derived growth factor $(54,98)$, insulin-like growth factor-I (54), epidermal growth factor, and basic fibroblast growth factor (44). On the other hand, transforming growth factor- $\beta$ is a pleiotropic factor whose mitogenic action depends on the 
target cell type. In addition, its action depends on the developmental origin, as we have shown that it inhibits fetal skin fibroblasts and stimulates adult ones to divide $(47,114)$. With this in mind, it has been proposed that transforming growth factor- $\beta 1$ inhibits also the proliferation of human adult gingival fibroblasts (92), as they express fetal-like characteristics (see also below). However, others have shown that transforming growth factor- $\beta 1$ stimulates the proliferation of gingival fibroblasts (153). Platelet-rich plasma, containing all the above mentioned factors, also stimulates gingival fibroblast proliferation (108). In vivo studies have shown in addition that epidermal growth factor, basic fibroblast growth factor (44) and transforming growth factor- $\beta 1$ (108) stimulate gingival cell proliferation and rapid tissue repair in various animal models. However, the topical use of growth factors towards wound healing has several limitations, including their short half-life in vivo. Towards a gene therapy for ulcer healing and periodontal tissue engineering, it has been shown that adenoviralmediated platelet-derived growth factor-B gene delivery stimulates the proliferation of gingival fibroblasts (87). Furthermore, proteomic analysis indicated that platelet-derived growth factor-B gene overexpression provokes a prolonged phosphorylation of protein kinase protein kinase B/Akt (87), which is linked to stimulated cell proliferation.

In the later stages of wound healing, the newly formed provisional extracellular matrix is replaced by granulation tissue. At this stage fibroblasts are transformed into myofibroblasts, characterized by an extended contractile apparatus and a marked increase in a-smooth muscle actin, the latter being typical of smooth muscle cells. Myofibroblasts play a critical role in tissue contraction, due to their ability to exert contractile forces (35). A major tool for the study of the cells' ability for contraction is their 3D culture in polymerized collagen gels, as these represent a closer approximation of the in vivo conditions compared to the classical 2D cultures, thus allowing the study of the biochemical, geometrical and mechanical interactions between cells and their extracellular environment (50). Several growth factors known to speed the healing process, such a platelet-derived growth factor, transforming growth factor- $\beta$, and insulin-like growth factors-I and II, have been shown to enhance the contraction of $3 \mathrm{D}$ collagen matrices populated by human gingival fibroblasts $(5$, 89). This phenomenon is most probably unrelated to the proliferative effect of these factors, as the time of observation for gel contraction is rather short (approx. 1 day) and, furthermore, it has been shown that the ability of growth factors to provoke a mitogenic effect is severely diminished in these $3 \mathrm{D}$ matrices (49). In the contraction process, the role of collagen-bonding integrin receptors as well as of the associated cytoskeleton is of obvious importance. In this vein, it has been shown that gingival fibroblasts express $\alpha 1$, $\alpha 2$ and $\alpha 11$ integrin chains that form heterodimers with $\beta 1$ integrin, and furthermore that insulin-like growth factor-II, which promotes collagen contraction, stimulates the increase of a11 integrin at the protein level. Finally, neutralizing antibodies against $\alpha 1$ and $\alpha 2$ integrin blocked 
collagen gel contraction only partially, while anti-a11 integrin siRNA had a more pronounced effect. Moreover, the combination of anti- $\alpha 11$ integrin siRNA with an anti- $\alpha 2$ integrin antibody totally abolished the contraction process (5). All these data indicate that $\alpha 2 \beta 1$ and $\alpha 11 \beta 1$ integrin complexes are the major integrins responsible for collagen contraction in human gingival fibroblasts. Integrins are linked with the underlying cytoskeleton and inhibition of cytoskeletal contraction, e.g. by demecolcine that depolymerizes microtubules, can also inhibit collagen gel contraction (89).

Interestingly, factors that affect wound healing, such as ethanol and non-steroidal anti-inflammatory drugs, have also been shown to inhibit the contraction process (89). Finally, nicotine can also interfere with the differentiation of gingival fibroblasts to myofibroblasts. In particular it has been shown that nicotine inhibits the transforming growth factor- $\beta$ mediated induction of $\alpha$-smooth muscle actin (39), the latter being crucial for the myofibroblast's contractile ability (60).

In this context, it is worth mentioning that in oral wounds, resident fibroblasts might no be the only cells giving rise to contractile myofibroblasts. In a rat model, it was shown that bone marrow-derived mesenchymal stem cells (labeled with green fluorescent protein) invaded healing wounds and differentiated into myofibroblasts (150). Moreover, these stem cells were preferentially recruited to oral mucosal rather than to skin wounds (151), perhaps explaining in part the larger healing potential of oral mucosa.

\section{How oral fibroblasts produce, remodel and interact with extracellular matrix in healing wounds}

Early during the healing of a skin or an oral wound, lost tissue is replaced by heavily vascularized granulation tissue, which then becomes re-epithelialized to seal the wound. To a large part, granulation tissue consists of a specialized, fetal-like extracellular matrix, which is synthesized, secreted and assembled by cytokine-activated fibroblasts that migrate into the wound bed (36). Like any other extracellular matrix, the one of the wound is composed of collagens characterized by glycine-proline-rich triple-helices, glycoproteins with $\mathrm{N}$-linked sugars, and proteoglycans with large O-linked glycosaminoglycan side chains (66). The early wound extracellular matrix is rich in collagen type III fibrils and other minor collagen types, in glycoproteins like fibronectin and tenascin- $C$ that regulate cell adhesion and migration (23), as well as in hyaluronic acid (a solube glycosaminoglycan) and proteoglycans. Due to the osmotic activity of their glycosaminoglycan side chains, the latter are responsible for the high water content of granulation tissue. Over a period of weeks, 
fibroblasts remodel the granulation tissue by degrading the provisional extracellular matrix and replacing it with more dense, less vascularized, fibrillar scar tissue rich in collagen type I (36). Whereas scars of the skin can persist for years, the entire wound healing process occurs more rapidly in the oral cavity, and most scars are further remodeled to mucosa or gingiva with a normal appearance (134).

In an early study, Qwarnstrom et al. (116) used a clever semi-3D culture system to carefully describe the steps of extracellular matrix assembly in an in vitro model for a healing oral wound. On top of a gingival fibroblast monolayer, they placed demineralized tooth slices at a distance of $0.5 \mathrm{~mm}$, and observed how the fibroblasts grew up on the slices and eventually filled the entire gap with extracellular matrix. By electron microscopy, a network of thin extracellular matrix fibrils was first found to accumulate in the cleft , and thicker crossstriated collagen fibrils appeared after 6 weeks in culture. By immunocytochemistry, the early fibrillar matrix was found to contain fibronectin, hyaluronic acid and other glycosaminoglycans, whereas major components of the late wound matrix were fibrillar collagen types I, III and V (116). The time course of extracellular matrix expression has also been studied in mucoperiosteal wounds in rats in vivo. Myofibroblasts positive for $\alpha$-smooth muscle actin were found between 4 and 22 days with a peak at 8 days, specifying the phase of wound contraction. Collagen I and III positive fibers increased in number until 8 days after wounding, after which the staining intensity for collagen III was diminished. At two months post-wounding, more transverse collagen I fibers and less collagen III and elastin fibers were found than in uninjured submucosa, indicating scar formation (25). Yet another study examined the changes in extracellular matrix expression during experimental gingivitis in human subjects. The inflammation phase was characterized by an increase in immunoreactivity for fibronectin and collagen III, and a decrease in collagen I. All changes were fully reversed in the repair phase (93).

As mentioned previously, the synthesis of proteoglycans by fibroblasts during early wound healing is stimulated directly by the pro-inflammatory cytokine interleukin-4 ; large proteoglycans (versican/perlecan-type) are induced more strongly than small ones (biglycan/decorin-type) (58). Bacterial lipopolysaccharide increases the synthesis of hyaluronic acid by gingival fibroblasts by $50 \%$ within 1-2 days. This response is blocked by indomethacin which blocks prostaglandin production, and therefore seems to be secondary to prostaglandin E2 synthesis that is stimulated by lipopolysaccharide in these cells (6). Another factor stimulating extracellular matrix production in granulation tissue is basic fibroblast growth factor. During early stages of wound healing in the gingiva, basic fibroblast growth factor is associated mainly with macrophages and mast cells in the granulation tissue. Later, it accumulates in myxoedematous stroma that is rich in proteoglycans (99). 
After the acute inflammation phase, probably the most important growth factors for granulation tissue formation are the transforming growth factor- $\beta \mathrm{s}$. They are not only essential for the differentiation of fibroblasts into myofibroblasts (and hence for wound contraction) as already mentioned, but they also directly or indirectly induce the genes for an entire set of extracellular matrix components (27). Topical application of transforming growth factor- $\beta 1$ can change extracellular matrix deposition in early gingival wound healing, as has been shown by immunocytochemistry in rats. In transforming growth factor- $\beta 1$ treated wounds, there was an increase in tenascin- $C$ and a concomitant decrease in heparan sulfate proteoglycan; at the same time, more proliferating fibroblasts and collagen IV-positive blood vessels were observed than in control wounds (109). Thus, transforming growth factor- $\beta 1$ promotes and accelerates granulation tissue formation. Granulation-tissue fibroblasts were compared with normal gingival fibroblasts in terms of their response to transforming growth factor- $\beta 1$ and extracellular matrix production. Fibroblast strains isolated from granulationtissue contained a variable proportion of contractile $\alpha$-smooth muscle actin-positive myofibroblasts, and expressed strongly elevated basal levels of biglycan, fibromodulin, versican, type I and III procollagen. Compared to normal gingival fibroblasts, they responded to transforming growth factor- $\beta 1$ with a higher induction of extracellular matrix proteins (56). Similarly, oral fibroblasts isolated from hereditary gingival fibromatosis patients were found to produce about twice the amount of fibronectin and collagen I per cell than normal gingival fibroblasts. These cells also secreted more transforming growth factor- $\beta 1$ and $-\beta 2$. Interestingly, neutralizing antibodies to both transforming growth factor- $\beta$ isoforms were able to reduce fibronectin as well as collagen I synthesis levels of fibromatosis-derived fibroblasts to those of normal gingival fibroblasts, indicating that increased extracellular matrix synthesis by the diseased cells is due to their autocrine stimulation with transforming growth factor- $\beta$. (143). The same might be true for activated granulation tissue fibroblasts in general (Fig. 1). A greater number of transforming growth factor- $\beta 1$-expressing fibroblasts is found in druginduced gingival overgrowth as well as hereditary gingival fibromatosis; thus there seems to be a clear relationship beween autocrine transforming growth factor- $\beta 1$ production and fibrosis (154). Whereas the genes for certain extracellular matrix proteins (e.g. collagen I, tenascin-C) are directly activated by transforming growth factor- $\beta$ signaling (27), many of its effects on extracellular matrix synthesis might be mediated indirectly by connective tissue growth factor. The latter is not a classical growth factor, but a small „matricellular" extracellular matrix protein secreted by fibroblasts in response to transforming growth factor$\beta$ (24). Although the mechanism is not understood in detail, connective tissue growth factor is a potent autocrine enhancer of fibroblast proliferation, migration and extracellular matrix deposition, and is thought to potentiate the pro-fibrotic action of transforming growth factor- $\beta$. 
Transcription factor Smad3 (which acts downstream of transforming growth factor- $\beta$ receptors) and mitogen-activated protein kinase ERK-1/2 coordinately mediate transforming growth factor- $\beta$-induced expression of connective tissue growth factor in human fibroblasts (83). Connective tissue growth factor has been shown to be induced by transforming growth factor- $\beta 1$ in human gingival as well as periodontal ligament fibroblasts (140).

Certain drugs specifically affect oral wound healing, apparently by inducing growth factors that stimulate extracellular matrix synthesis in gingival and mucosal fibroblasts. For example, the immunosuppressive drug cyclosporin appears to induce gingival overgrowth by up-regulating transforming growth factor- $\beta$ and platelet-derived growth factor, and hence by stimulating excess extracellular matrix production (12). The antiepileptic drug phenytoin (diphenylhydantoin), which is also known to promote gingival overgrowth, stimulates hydroxyproline incorporation into newly synthesized collagen and thereby leads to a higher tensile strength of scar tissue. Presumably, phenytoin induces hypertrophic scar formation and overgrowth by stimulating inflammation and accelerating the wound healing process (30). More recent microarray data showed that in dermal fibroblasts, phenytoin induced about 1500 genes more than 2.5-fold, among them major growth factors and their receptors, as well as extracellular matrix proteins (collagen I, fibronectin, laminin) and extracellular matrix-degrading enzymes (matrix metalloproteinase-1) (137). Conversely, other drugs have been reported to suppress extracellular matrix expression by oral fibroblasts, and are therefore likely to compromize wound healing. An example are biphosphonates, which are used to treat osteoporosis but may have severe side effects such as osteonecrosis of the jaw. These compounds reduce the production of collagen types I, III and V not only in osteoblasts but also in gingival fibroblasts (127).

Interestingly, various types of oral fibroblasts exhibit characteristic differences in their extracellular matrix production. In general, periodontal ligament fibroblasts were found to produce more bulk extracellular matrix than gingival fibroblasts (63). In contrast to gingival fibroblasts, periodontal ligament fibroblasts express certain osteoblast-specific markers (alkaline phosphatase, osteopontin, osteocalcin) although they fail to mineralize (71). In one specific study, gingival fibroblasts, periodontal ligament fibroblasts, and cells derived from a guided periodontal tissue regeneration procedure ("regenerating tissue fibroblasts") were compared in terms of their growth characteristics and proteoglycan expression patterns. Gingival fibroblasts and regenerating tissue fibroblasts proliferated more quickly than periodontal ligament fibroblasts. Of the small proteoglycans, decorin expression was strongest in gingival fibroblasts, whereas biglycan mRNA was highest in regenerating tissue fibroblasts. Expression of the large proteoglycan versican was high in gingival and periodontal fibroblasts but not regenerating tissue fibroblasts. Thus, although regenerating 
tissue fibroblasts were derived from periodontal ligament fibroblasts, they divided more rapidly and showed a specific proteoglycan expression pattern (68). In addition to cellautonomous differences, crosstalk with adjacent epithelia appears to regulate extracellular matrix production by various fibroblast types. In cocultures, oral epithelial cells influence the expression of extracellular matrix by oral fibroblasts depending on their site of origin. For example, gingival epithelial cells do not affect the expression of collagen I and III in gingival fibroblasts but suppress these genes in periodontal fibroblasts (62). In summary, different oral fibroblast types are distinct in their extracellular matrix expression pattern in healthy tissues but also change it in context-specific ways during wound healing (42).

Not only the production of extracellular matrix, but also its turnover and remodeling in the course of oral wound healing are important. Extracellular matrix degradation is achieved by a multitude of proteolytic enzymes, the most important being the family of matrix metalloproteinases (75). Compared to dermal fibroblasts, there is not much literature yet on how oral fibroblasts use matrix metalloproteinases to degrade their extracellular matrix. Human dermal and gingival fibroblasts were compared in terms of their capability to remodel the extracellular matrix when cultured in floating collagen gels. No differences were found between the two cell types in cell numbers over time in culture, nor in their speed of contracting the collagen lattice. In collagen gel cultures of both dermal and gingival fibroblasts, a transient accumulation and later disappearance of collagen III and fibrillin I was observed, concomitantly with the expression of matrix metalloproteinases and tissue inhibitors of metalloproteinases (TIMPs), their negative regulators. This remodeling was reported to be more rapid and intense with gingival than with dermal fibroblasts (20). For both gingival and periodontal ligament fibroblasts, matrix metalloproteinase-2 is the major gelatinase detected in zymograms, whereas oral keratinocytes primarily secrete matrix metalloproteinase-9 (80). In gingival fibroblasts, mRNA expession for matrix metalloproteinase-1 (collagenase-1), matrix metalloproteinase-2, TIMP-1 and TIMP-2 were all strongly suppressed by the corticosteroid analog dexamethasone (80). Epidermal growth factor (which is secreted by activated platelets, macrophages and fibroblasts) seems to be a major growth factor inducing matrix metalloproteinases in human gingival fibroblasts. Very low epidermal growth factor concentrations $\left(10^{-12} \mathrm{M}\right)$ were found to increase the expression of matrix metalloproteinase-11 mRNA and protein; higher concentations $\left(10^{-6} \mathrm{M}\right)$ also induced matrix metalloproteinase-1, -3 and -7 . In contrast, matrix metalloproteinase-2 as well as TIMP-1 and -2 expression were not affected by epidermal growth factor (26). Matrix metalloproteinase-13 (collagenase-3) has gained attention because of its distinct expression pattern in wound healing. In humans, matrix metalloproteinase-13 is produced by fibroblasts in chronic cutaneous ulcers, but is absent from normally healing adult skin wounds. In contrast, fibroblasts express matrix metalloproteinase-13 in adult gingival as well as in fetal 
skin wounds, which are both characterized by rapid collagen remodeling and scarless healing (146). When adult human skin fibroblasts were transfected with matrix metalloproteinase-13, their ability to contract and remodel a 3D collagen matrix in culture was greatly enhanced. Matrix metalloproteinase-13 expression also promoted survival and proliferation of skin fibroblasts in floating collagen gels, presumably by activating protein kinase B/Akt (which regulates protein synthesis and cell growth) and the mitogen-activated protein kinase ERK-1/2 (146). Thus, oral fibroblasts appear to be distinct from normal skin fibroblasts in their ability to express matrix metalloproteinase-13. This enzyme is likely to be important for rapid extracellular matrix remodeling and scarless wound healing in the fetus and in the adult oral cavity, but might also be involved in ulcer formation in the case of chronic inflammation of the skin.

Matrix metalloproteinases are the most important but not the only proteinases involved in wound healing. Even before granulation tissue is formed, a first provisional extracellular matrix is provided by the fibrin clot into which immune cells, fibroblasts and keratinocytes can move, and which needs to be removed by plasminolysis before further repair can occur. In contrast to dermal fibroblasts, oral fibroblasts seem to be directly involved in removal of a fibrin clot before they start producing the extracellular matrix of granulation tissue. Human gingival fibroblasts express a low basic level of urokinase-type plasminogen activator, which is however strongly stimulated by epidermal growth factor via mitogen-activated protein kinase (JNK and ERK-1/2) dependent pathways (130). In an earlier interesting study, dermal and gingival fibroblasts were cultured in either collagen or fibrin 3D-gels. In collagen, both fibroblast types had similar morphology, showed similar rates of collagen lattice contraction with little collagen degradation. In contrast, gingival but not dermal fibroblasts were found to completely digest a fibrin lattice within less than 8 days. This seemed to be due to the high level of tissue-type plasminogen activator, which was induced in gingival fibroblasts in fibrin 3D-gels but not in monolayer culture. Thus, the surrounding extracellular matrix itself can control the expression of specific matrix proteinases in gingival fibroblasts. Little fibrinolysis by gingival fibroblasts was observed with plasminogen-depleted fibrin gels or in the presence of an inhibitor of tissue-type plasminogen activator ( $\varepsilon$-amino-caproic acid) (88).

In this context, it should be added that extracellular matrix turnover is accomplished not only by extracellular proteases like matrix metalloproteinases or plasminogen activators, but also by cellular uptake and intracellular degradation of extracellular matrix fragments. Endo180 is a non-integrin cell membrane receptor involved in the binding and internalization of partially digested (denatured) collagen. Due to induction by relevant growth factors, expression of Endo180 is spatially and temporally increased during gingival wound healing, mainly in macrophages, myofibroblasts, pericytes and endothelial cells (61). 
Both the production and the remodeling of wound extracellular matrix by oral fibroblasts could not occur without a close interaction between cells and their surrounding matrix. Fibroblasts attach to the extracellular matrix primarily by means of integrins, heterodimeric cell membrane receptors (65). Although constitutively present on cell surfaces, most integrins need to be activated to firmly connect their extracellular matrix ligands and with the cell's cytoskeleton. Integrins are essential for attachment, spreading and migration of cells on extracellular matrix. In the case of fibroblasts and epithelial cells, integrins are in addition very important for extracellular matrix assembly: These cells are able to capture secreted extracellular matrix proteins on their surfaces, and then use cytoskeletal traction forces to spin them into fibrils and networks (128).

Unfortunately, not much is known yet about the function of specific integrins expressed on oral fibroblasts. One recent study showed that different cell types present in oral wounds are distinguished by their differential motility on extracellular matrix proteins in vitro. In general, the migration speed of gingival fibroblasts on collagens was found to be about twice as high as that of periodontal ligament fibroblasts, whereas osteoblasts were essentially non-motile (81). In addition and interestingly, different extracellular matrix components could provoke distinct locomotion responses: gingival fibroblasts migrated rapidly on collagen III, moderately on collagen $\mathrm{V}$ and more slowly on collagen I. This is probably due to the engagement of different integrin receptors: gingival fibroblasts appear to use $\alpha 1 \beta 1$ integrin to migrate on collagen III, and $\alpha 2 \beta 1$ integrin to move on collagen I (81). Another relevant study investigated the role of fibronectin and its receptor integrin $\alpha 5 \beta 1$ in the expression of alkaline phosphatase by gingival fibroblasts. During wound healing, fibroblasts in fibronectin-rich granulation tissue express alkaline phosphatase. Gingival fibroblasts in culture started synthesizing alkaline phosphatase in response to ascorbic acid; this response was abolished by blocking antibodies to $\alpha 5 \beta 1$ integrin. Ascorbic acid-induced alkaline phosphatase expression was increased when gingival fibroblasts were plated on exogenous fibronectin, and suppressed when they were cultured on or in fibrillar collagen gels. Alkaline phosphatase induction was also blocked by dehydroxyproline, which inhibits fibronectin assembly and cell spreading on fibronectin (1). These results show that fibronectin and its receptor, integrin $\alpha 5 \beta 1$, directly control the expression of a marker gene for activated gingival fibroblasts in granulation tissue.

Certain evidence also indicates that enamel proteins might control gene expression of gingival and periodontal fibroblasts via an adhesion- and presumably integrin-based mechanism. Enamel matrix derivative, extracted from pig teeth and consisting largely of the extracellular matrix proteins amelogenin and ameloblastin, is widely employed in the clinic to support oral wound healing. Its use was originally intended for improving enamel regeneration, for which the evidence is sparse. However, a body of literature indicates that 
enamel matrix derivative is beneficial for regenerative periodontal therapy, although the mechanism is not clear yet. Enamel matrix derivative seems to stimulate cell adhesion and the expression of growth factors and extracellular matrix proteins by periodontal ligament cells (14). Enamel matrix derivative was reported to induce hyaluronic acid and proteoglycan synthesis by cultured human gingival and periodontal fibroblasts. Specifically, it increased expression of hyaluronic acid syntase-2 and -3 , versican, biglycan and decorin. The effect was similar to, but potentially stronger than with mitogenic cytokines (53). Recently, it was shown that fibroblasts adhere to amelogenin and ameloblastin via cell-secreted fibronectin; in ameloblastin, a short amino acid sequence was identified that mediated this interaction (10). Thus, pericellular fibronectin appears to form the link between fibroblasts and enamel proteins, and again the fibronectin receptor $\alpha 5 \beta 1$ integrin might mediate at least some of the effects of enamel matrix proteins on gene expression of oral cells.

Finally, it is of clinical relevance that the interactions of fibroblasts with their extracellular matrix can change with age and disease, thus affecting oral wound healing. For example, enhanced blood sugar levels associated with diabetes can induce the nonenzymatic glycation of extracellular matrix and other proteins. The so-called advanced glycation end products have been linked to the pathogenic mechanism of diabetes. Accordingly, human gingival and periodontal ligament fibroblasts were reported to attach and migrate poorly on fibronectin or collagen I that had been glycated non-enzymatically in vitro (100). Thus, glycation of extracellular matrix proteins could contribute to the impaired oral wound healing observed in elderly people and patients with diabetes.

\section{Responses of oral fibroblasts to mechanical stress}

We have seen earlier that fibroblasts in healthy tissues are considered as "sentinel" cells: they are able to detect and respond to environmental cues (e.g. bacterial components or cytokines released by immune cells) that are first signs of injury and inflammation. In addition, fibroblasts are known to monitor yet another type of deviation from tissue homeostasis, namely changes in mechanical stress. Physical load is recognized to be very important for connective tissue development, maintenance, and remodeling (22). Of course, the most obvious example in oral biology is orthodontic tooth movement, which would not occur without the ability of periodontal ligament fibroblasts to sense applied tensile and compressive stresses, and to translate this information into instructions for other cells, mainly mesenchymal and hematopoietic stem cells. These then give rise to osteoblasts and osteoclasts, respectively, which remodel the alveolar bone (90). In addition, mechanical 
homeostasis is disturbed in every wound, with implications for healing: Depending on the specific site of an injury, excess tensile strain might build up locally at a wound margin, which favors hypertrophic scarring at this position (36). How do fibroblasts sense changes in mechanical stress in their extracellular matrix environment? As mentiond before, integrin receptors physically connect the extracellular matrix with the cell's cytoskeleton and transmit forces in both directions. Depending on the stiffness of the extracellular matrix, externally appied stress (force per area) results in in a certain extracellular matrix strain (deformation), which is transmitted to the cell's cytoskeleton. To maintain shape, fibroblasts counteract applied force with cytoskeletal traction; thus extracellular matrix strain results in increased cytoskeletal stress (21). Certain integrin-asociated adaptor proteins and cation channels can act as "strain gauges": they undergo conformational changes in response to applied force, change their activity, and thereby transduce a mechanical into a chemical signal. The major signaling pathways triggered by mechanical stimuli in an integrin-dependent way in fibroblasts are mitogen-activated protein kinases, $\mathrm{Ca}^{2+}$, nuclear factor-kB, and RhoA/Rhodependent kinase. As all pathways are also activated by growth factors and cytokines, mechanical stress can act synergistically with these factors to cause changes in gene expression (22).

As was reported also for embryonic skin fibroblasts (123), oral fibroblasts respond to mechanical stress by a rapid contraction of their actomyosin network, with resulting changes in cytoskeletal structure. When force was applied to collagen-coated magnetic beads attached to the surface of gingival fibroblasts, the cells reacted with rapid $\mathrm{Ca}^{2+}$ influx, phosporylation of focal adhesion proteins like paxillin, and an increase in actin polymerization and in stiffness of the cortical cytoskeleton (48). These authors speculated that the actin response may be cytoprotective by strengthening cytoskeletal integrity and protecting cells from further bouts of tensile strain. In an even earlier study, gingival and periodontal ligament fibroblasts were compared in terms of their cytoskeletal changes in response to a one-step (static) increase in tensile strain of their substrate by $3 \%$; filamentous F-actin was quantified by phalloidin staining. Gingival fibroblasts reacted to static strain with a rapid drop in F-actin, followed by a two-fold increase after one minute. After three minutes, the cells contracted. Periodontal fibroblasts exhibited twice the amount of F-actin at rest compared to their gingival counterparts, and although they showed no additional increase in F-actin after stretching, they contracted as well (111). In addition, oral fibroblasts might differ from dermal fibroblasts in their contractility in response to mechanical stress in wounds. Wound-inducible transcript 3.0 is a very interesting cytoskeletal protein homologous to the myosin II coiled-coil domain, which is specifically increased in oral mucosa but not in skin during wound healing. Wound-inducible transcript 3.0 seems to be responsible for the 
enhanced collagen matrix contraction and cell migration of wound-derived oral fibroblasts compared to dermal fibroblasts (136).

As mentioned, mechanical stress applied to integrins on the fibroblast surface triggers various signaling pathways that directly and rapidly change gene transcription. Actin assembly and contraction in response to mechanical stress is triggered by integrindependent activation of the small GTPase RhoA. As a direct consequence, a transcriptional regulator called megakaryocytic leukemia-1 (MKL1/MAL) translocates from the cytoplasm to the nucleus and mediates the rapid activation of mechanoresponsive genes such as $\alpha-$ smooth mucle actin (155) or tenascin-C (4). Periodontal fibroblasts were reported to react to static substrate strain with an increase in signaling by small GTPases Rab and Rho, mitogen-activated protein kinases, and consequently an activation of transcription factors cJun and c-Fos $(8,9,76)$. In gingival fibroblasts, force was found to recruit the microtubulebinding protein CLIP-170 and a-tubulin to focal adhesions and to increase the expression of filamin A, an actin-binding protein (28). Induction of filamin A by tensile strain in gingival fibroblasts was shown to depend on p38-mitogen-activated protein kinase-dependent phosphorylation of transcription factor Sp1, which then bound and activated the filamin A gene promoter (29). Secondary to such rapid changes in cytoskeletal structure and gene expression, mechanical stress influences cell proliferation and survival of oral fibroblasts. Cyclic strain delivers anti-apoptotic (such as retention of FoxO protein in the cytoplasm) and proliferative signals (such as activation of mitogen-activated protein kinase ERK and increased expression of proliferating cell nuclear antigen) to gingival fibroblasts (32).

An important secondary mediator of the response of fibroblasts to mechanical stress is again transforming growth factor- $\beta$. Cyclic substrate strain was reported to increase the secretion of transforming growth factor- $\beta 1$ by periodontal ligament cells but not gingival fibroblasts, whereas strain inhibited the release of macrophage-colony stimulating factor (a growth/differentiation factor for osteoclasts) from both cell types (74). In apparant contrast to this early study, a very recent paper demonstrated that cyclic substrate strain caused the rapid activation of latent transforming growth factor- $\beta 1$ in cultures of gingival fibroblasts; consequently, several pro-proliferative and pro-fibrotic genes were upregulated, among them for connective tissue growth factor. Compared to dermal fibroblasts, this fibrogenic response was considerably reduced, however (52). In addition to stimulating extracellular matrix expression, transforming growth factor- $\beta 1$ also activates RhoA, induces actin stress fiber formation, and reinforces vinculin-positive focal adhesions in human gingival fibroblasts; all these events were blocked by inhibition of RhoA/Rho-dependent kinase. Transforming growth factor- $\beta 1$ also induced $\alpha$-smooth muscle actin expession in a mitogen-activated protein kinase JNK-dependent manner in these cells (129). Thus, transforming growth 
factor- $\beta 1$ stimulates myofibroblast differentiation of gingival fibroblasts at least in part by promoting cell contractility.

Expectedly, mechanical stress modulates the expression of many stuctural extracellular matrix components as well as extracellular matrix-degrading enzymes, although it is often not clear whether the effect is direct (via immediate activation of RhoA or mitogenactivated protein kinase pathways) or due to the strain-induced release of factors such as transforming growth factor- $\beta$. Periodontal ligament and gingival fibroblasts were subjected to continous (static) stretch and the mRNAs for matrix metalloproteinases, their inhibitors, and integrins quantified. Whereas under these conditions matrix metalloproteinases and their tissue inhibitors (matrix metalloproteinase-1, matrix metalloproteinase-2, TIMP-1 and TIMP2) were induced in both cell types, they showed a differential response to stretch in terms of expression of various integrin chains (11). In periodontal ligament fibroblasts, compressive centrifugal force increased the mRNA level for matrix metalloproteinase1, but had no effect on collagen I and TIMP expression (118). Centrifugal force applied to gingival fibroblasts was found to upregulate the expression of collagen I and osteopontin via mitogen-activated protein kinase ERK-1/2 and/or JNK signaling, respectively (70). However, these responses of oral fibroblasts to mechanical stress might be modulated by many environmental and genetic factors. In a study where gingival fibroblast strains were isolated from several human subjects and compared, pronounced interindividual differences were found in their response to cyclic strain in terms of changes in the expression of various extracellular matrix proteins (51). Interestingly, published evidence indicates that toothbrushing is a physiologically relevant mechanical stimulus for increasing extracellular matrix production by gingival fibroblasts in vivo. A study in dogs demonstrated that toothbrushing over three weeks with an applied force of $2 \mathrm{~N}$ for 10-20 seconds daily significantly increased fibroblast proliferation and procollagen type I synthesis in the gingiva (144). Periodontal ligament cells in vivo were not affected by toothbrushing (145), presumably because they are mechanically shielded by alveolar bone. In a rat model, toothbrushing accelerated the healing of gingivitis by reducing the infiltration of polymorphonuclear leukocytes and enhancing gingival fibroblast proliferation and collagen synthesis (37).

Finally, mechanical stress controls the production and release by oral fibroblasts of inflammatory mediators and of substances involved in bone remodeling. For example, both periodontal ligament and gingival fibroblasts react to pulsating fluid flow with an acute increase in prostaglandin-E2 production after one hour. In contrast to gingival fibroblasts, periodontal ligament cells also release nitric oxide in response to fluid flow, and their prostaglandin-E2 release continues after stopping the flow (149). Thus, periodontal ligament fibroblasts seem more responsive to fluid flow and resemble osteoblasts in this respect. A cytokine induced and released after applying cyclic strain to gingival fibroblasts is migration 
inhibitory factor MIF (97). In accordance with an important function in orthodontic tooth movement, periodontal ligament fibroblasts are also well known to secrete factors that control bone remodeling; among them receptor activator of NFKB ligand (RANKL), which stimulates, and osteoprotegerin, which inhibits osteoclast differentiation. In a tissueengineered 3D model for periodontal ligament, static compression induced expression of RANKL and other osteoclastogenesis inducers (84). A study in humans showed that upon orthodontic tooth movement, the concentration of RANKL increased and that of osteoprotegerin decreased in crevicular fluid obtained from the compression side of the tooth, indicating stimulation of osteoclastogenesis; the same changes were seen after subjecting periodontal ligament cells to compressive stress in vitro by putting a weight on top of a monolayer culture (102). However, this simple method is likely to generate severe hypoxic conditions for the cells, which might obscure the mechanical effect. Indeed, and in obvious contrast to the latter results, another group reported that compressive centrifugal force increased the osteoprotegerin production of both gingival (78) and periodontal ligament fibroblasts (79). Yet another study with a different focus reported that $10 \%$ static tensile stress to the substrate for 12 hours decreased RANKL and increased osteoprotegerin expression by periodontal ligament fibroblasts (133). To explain the regulation of osteoclastogenesis during orthodontic tooth movement, compressive stress should decrease and tensile stress increase osteoprotegerin production by periodontal ligament cells in vitro; the opposite should be true for RANKL. Surprisingly, however, there are only very few technically sound reports on this important subject, and so far no direct comparison of the effects of the two opposite modes of mechanical stress on oral fibroblasts has been published.

\section{Fetal-like responses of gingival fibroblasts and the role of aging in vivo and in vitro}

In most tissues, like in skin, wounds heal in an orderly fashion proceeding through several stages, i.e. haemostasis, inflammation, proliferation and remodeling of the newly formed extracellular matrix, towards a tissue resembling the original unwounded one. However, scarring represents a major problem in tissue quality and function. In contrast, in many fetal tissues and especially in the first stages of gestation a different repair strategy is observed, characterized by a lower inflammatory reaction, a reduced angiogenesis, an increased contraction and finally by the absence of scar formation (41). Interestingly, in the adults, oral wounds exhibit privileged healing, characterized by rapidity and lack of scar formation, like in fetal wounds (134). In this vein, wounds in oral mucosa, compared to dermal wounds, exhibit significantly lower levels of macrophages, neutrophils and T-cell infiltration, as well as lower 
concentrations of the inflammatory cytokine interleukin-6 or of the pro-fibrotic cytokine transforming growth factor- $\beta$ (139), while they are characterized by lower bed vascularity and decreased levels of the pro-angiogenic factor, vascular endothelial growth factor (138). As fibroblasts are major players in the healing process, the role of gingival fibroblasts in this unique repair strategy has been investigated, in most cases, in comparison with adult skin fibroblasts. It has been shown that oral mucosa fibroblasts are able to contract more rapidly fibroblast-populated collagen lattices (134). One more characteristic of fetal wounds is the rapid movement of fibroblasts into the wounded area, as to initiate quickly tissue remodeling. This is achieved by the function of matrix metalloproteases that can degrade extracellular matrix components, thus facilitating cell migration. Interestingly, oral mucosal fibroblasts exhibit increased levels of activated matrix metalloproteinase-2. This is most probably not due to an increased expression of matrix metalloproteinase-2 at the transcriptional level but rather to a decreased activity of tissue inhibitors of metalloproteases (TIMP)-1 and -2 (135).

Fetal skin wounds are also characterized by a decreased presence of the profibrotic cytokine transforming growth factor- $\beta 1$, and several lines of evidence indicate that this may contribute to the scarless fetal tissue repair (86). However, human fetal skin fibroblasts differ from their adult counterparts in terms of their proliferative response to transforming growth factor- $\beta$. In particular, transforming growth factor- $\beta$ inhibits the proliferation of fetal cells, while it stimulates adult ones $(47,114)$. Interestingly, it had been reported that transforming growth factor- $\beta 1$ induces an antiproliferative response in oral fibroblasts, through Smad3 signaling. This difference in the response of oral and dermal fibroblasts seems to be linked to the differential expression of hyaluronic acid produced by these two cell types (92). All the above indicates that gingival fibroblasts possess unique intrinsic features that may be responsible for the fetal-like tissue repair of oral mucosa. This may be explained by the different embryological origin of oral mucosal fibroblasts (neural crest) and skin fibroblasts (mesoderm) (38). However, while cells from the papillary tips display some fetal-like characteristics, this is not the case for cells obtained from the deeper reticular tissue, which express rather adult-like characteristics, indicating the existence of intra-site heterogeneity in the characteristics of oral mucosa fibroblasts (67).

Aging is linked with a decrease in the tissue repair ability. In this direction, gingival fibroblasts from aged humans or animals express altered functions related to wound healing. In particular, fibroblasts from aged tissues exhibit a decline in their proliferative capacity (73), while in response to lipopolysaccharide they produce increased amounts of inflammatory mediators, such as prostaglandin-E2, interleukin- $1 \beta$ and interleukin- $6(3,107)$. Finally, fibroblasts from adult donors were less able for the contraction of fibroblast-populated collagen lattices compared to cells from children (134). One of the mechanisms that has been proposed to contribute to aging and to age-related pathologies is cellular senescence 
(15). Normal fibroblasts have a limited lifespan when they are cultured in vitro due to telomere shortening (57). Alternatively, cells can become senescent when exposed to repeated doses of stresses at sub-cytotoxic levels in a telomere-shortening independent manner (15). Senescent cells may contribute to the age-related impaired wound repair due to their inability to proliferate, as well as to their pro-inflammatory phenotype, as they overexpress matrix metalloproteinases, growth factors, inflammatory cytokines and other inflammatory mediators (126). Interestingly, oral mucosal fibroblasts exhibit an increased lifespan compared to patient-matched skin fibroblasts, and this difference is not due to telomerase expression (38). However, senescent gingival fibroblasts exhibit a much more intense production of the pro-inflammatory cytokine interleukin- 6 in response to lipopolysaccharide, compared to young (early-passage) fibroblasts (105).

\section{Conclusions}

Fibroblasts are cells of mesenchymal origin that are responsible for the production of most extracellular matrix in connective tissues, and are essential for wound healing and repair. Fibroblasts from different tissue origins are distinct in terms of their gene expression profile, growth characteristics, motility, and other traits. Due to their specific developmental origin and location, oral fibroblasts respond distinctly to the challenge of a wound, allowing them to cope optimally with the special conditions of the oral cavity. The understanding of the unique characteristics and the role of oral fibroblasts in wound healing and repair as well as the control mechanisms of their function is mandatory for developing new strategies to control the intraoral wound healing processes of the individual patient. 


\section{References}

1. Abe $\mathrm{T}$, Abe $\mathrm{Y}$, Aida $\mathrm{Y}$, Hara $\mathrm{Y}$, Maeda K. Extracellular matrix regulates induction of alkaline phosphatase expression by ascorbic acid in human fibroblasts. $J$ Cell Physiol 2001: 189: 144-151.

2. Abiko Y, Arai J, Matsuzawa K, Inoue T, Shimono M, Kaku T. Human gingival fibroblast migration promoted by platelet-derived growth factor on titanium is correlated with release of urokinase type plasminogen activator. Bull Tokyo Dent Coll 1996: 37: 113-118.

3. Abiko Y, Shimizu N, Yamaguchi M, Suzuki H, Takiguchi H. Effect of aging on functional changes of periodontal tissue cells. Ann Periodontol 1998: 3: 350-369.

4. Asparuhova MB, Ferralli J, Chiquet M, Chiquet-Ehrismann R. The transcriptional regulator megakaryoblastic leukemia-1 mediates serum response factor-independent activation of tenascin-C transcription by mechanical stress. FASEB J 2011: 25: 34773488.

5. Barczyk MM, Olsen LH, da Franca P, Loos BG, Mustafa K, Gullberg D, Bolstad AI. A role for alpha11beta1 integrin in the human periodontal ligament. J Dent Res 2009: 88: 621-626.

6. Bartold PM. Lipopolysaccharide stimulation of hyaluronate synthesis by human gingival fibroblasts in vitro. Arch Oral Biol 1991: 36: 791-797.

7. Bartold PM, Narayanan AS, Page RC. Platelet-derived growth factor reduces the inhibitory effects of lipopolysaccharide on gingival fibroblast proliferation. $J$ Periodontal Res 1992: 27: 499-505.

8. Basdra EK. Biological reactions to orthodontic tooth movement. J Orofac Orthop 1997: 58: 2-15.

9. Basdra EK, Papavassiliou AG, Huber LA. Rab and rho GTPases are involved in specific response of periodontal ligament fibroblasts to mechanical stretching. Biochim Biophys Acta 1995: 1268: 209-213.

10. Beyeler M, Schild C, Lutz R, Chiquet M, Trueb B. Identification of a fibronectin interaction site in the extracellular matrix protein ameloblastin. Exp Cell Res 2010: 316: 1202-1212.

11. Bolcato-Bellemin AL, Elkaim R, Abehsera A, Fausser JL, Haikel Y, Tenenbaum H. Expression of mRNAs encoding for alpha and beta integrin subunits, MMPs, and TIMPs in stretched human periodontal ligament and gingival fibroblasts. J Dent Res 2000: 79: 1712-1716.

12. Boltchi FE, Rees TD, lacopino AM. Cyclosporine A-induced gingival overgrowth: a comprehensive review. Quintessence Int 1999: 30: 775-783.

13. Bordin S, Flemmig TF, Verardi S. Role of fibroblast populations in peri-implantitis. Int J Oral Maxillofac Implants 2009: 24: 197-204.

14. Bosshardt DD. Biological mediators and periodontal regeneration: a review of enamel matrix proteins at the cellular and molecular levels. J Clin Periodontol 2008: 35: 87-105.

15. Campisi J, d'Adda di Fagagna F. Cellular senescence: when bad things happen to good cells. Nat Rev Mol Cell Biol 2007: 8: 729-740.

16. Cerutis DR, Dreyer A, Cordini F, McVaney TP, Mattson JS, Parrish LC, Romito L, Huebner GR, Jabro M. Lysophosphatidic acid modulates the regenerative responses of human gingival fibroblasts and enhances the actions of platelet-derived growth factor. J Periodontol 2004: 75: 297-305.

17. Cerutis DR, Dreyer AC, Vierra MJ, King JP, Wagner DJ, Fimple JL, Cordini F, McVaney TP, Parrish LC, Wilwerding TM, Mattson JS. Lysophosphatidic acid modulates the healing responses of human periodontal ligament fibroblasts and enhances the actions of platelet-derived growth factor. J Periodontol 2007: 78: 11361145. 
18. Chan CP, Chang MC, Wang YJ, Chen LI, Tsai YL, Lee JJ, Jia HW, Jeng JH. Thrombin activates Ras-CREB/ATF-1 signaling and stimulates c-fos, c-jun, and cmyc expression in human gingival fibroblasts. J Periodontol 2008: 79: 1248-1254.

19. Chang MC, Chan CP, Wu HL, Chen RS, Lan WH, Chen YJ, Jeng JH. Thrombinstimulated growth, clustering, and collagen lattice contraction of human gingival fibroblasts is associated with its protease activity. $J$ Periodontol 2001: 72: 303-313.

20. Chaussain Miller C, Septier D, Bonnefoix M, Lecolle S, Lebreton-Decoster C, Coulomb B, Pellat B, Godeau G. Human dermal and gingival fibroblasts in a threedimensional culture: a comparative study on matrix remodeling. Clin Oral Investig 2002: 6: 39-50.

21. Chen CS. Mechanotransduction - a field pulling together? J Cell Sci 2008: 121: 32853292.

22. Chiquet M, Gelman L, Lutz R, Maier S. From mechanotransduction to extracellular matrix gene expression in fibroblasts. Biochim Biophys Acta 2009: 1793: 911-920.

23. Chiquet-Ehrismann $\mathrm{R}$, Chiquet $\mathrm{M}$. Tenascins: regulation and putative functions during pathological stress. J Pathol 2003: 200: 488-499.

24. Cicha I, Goppelt-Struebe M. Connective tissue growth factor: context-dependent functions and mechanisms of regulation. Biofactors 2009: 35: 200-208.

25. Cornelissen AM, Stoop R, Von den Hoff HW, Maltha JC, Kuijpers-Jagtman AM. Myofibroblasts and matrix components in healing palatal wounds in the rat. $J$ Oral Pathol Med 2000: 29: 1-7.

26. Cury PR, de Araujo VC, Canavez F, Furuse C, Leite KR, de Araujo NS. The effect of epidermal growth factor on matrix metalloproteinases and tissue inhibitors of metalloproteinase gene expression in cultured human gingival fibroblasts. Arch Oral Biol 2007: 52: 585-590.

27. Cutroneo KR. TGF-beta-induced fibrosis and SMAD signaling: oligo decoys as natural therapeutics for inhibition of tissue fibrosis and scarring. Wound Repair Regen 2007: 15 Suppl 1: S54-60.

28. D'Addario M, Arora PD, Ellen RP, McCulloch CA. Regulation of tension-induced mechanotranscriptional signals by the microtubule network in fibroblasts. $\mathrm{J} \mathrm{Biol}$ Chem 2003: 278: 53090-53097.

29. D'Addario M, Arora PD, McCulloch CA. Role of p38 in stress activation of Sp1. Gene 2006: 379: 51-61.

30. DaCosta ML, Regan MC, al Sader M, Leader M, Bouchier-Hayes D. Diphenylhydantoin sodium promotes early and marked angiogenesis and results in increased collagen deposition and tensile strength in healing wounds. Surgery 1998: 123: 287-293.

31. Dale BA, Fredericks LP. Antimicrobial peptides in the oral environment: expression and function in health and disease. Curr Issues Mol Biol 2005: 7: 119-133.

32. Danciu TE, Gagari E, Adam RM, Damoulis PD, Freeman MR. Mechanical strain delivers anti-apoptotic and proliferative signals to gingival fibroblasts. $J$ Dent Res 2004: 83: 596-601.

33. Das SJ, Olsen I. Keratinocyte growth factor is upregulated by the hyperplasiainducing drug nifedipine. Cytokine 2000: 12: 1566-1569.

34. Das SJ, Olsen I. Up-regulation of keratinocyte growth factor and receptor: a possible mechanism of action of phenytoin in wound healing. Biochem Biophys Res Commun 2001: 282: 875-881.

35. Desmouliere A, Darby IA, Gabbiani G. Normal and pathologic soft tissue remodeling: role of the myofibroblast, with special emphasis on liver and kidney fibrosis. Lab Invest 2003: 83: 1689-1707.

36. Eckes B, Nischt R, Krieg T. Cell-matrix interactions in dermal repair and scarring. Fibrogenesis Tissue Repair 2010: 3: 4.

37. Ekuni D, Yamanaka R, Yamamoto T, Miyauchi M, Takata T, Watanabe T. Effects of mechanical stimulation by a powered toothbrush on the healing of periodontal tissue in a rat model of periodontal disease. J Periodontal Res 2010: 45: 45-51. 
38. Enoch S, Wall I, Peake M, Davies L, Farrier J, Giles P, Baird D, Kipling D, Price P, Moseley R, Thomas D, Stephens P. Increased oral fibroblast lifespan is telomeraseindependent. J Dent Res 2009: 88: 916-921.

39. Fang Y, Svoboda KK. Nicotine inhibits myofibroblast differentiation in human gingival fibroblasts. J Cell Biochem 2005: 95: 1108-1119.

40. Fedyk ER, Jones D, Critchley HO, Phipps RP, Blieden TM, Springer TA. Expression of stromal-derived factor- 1 is decreased by IL-1 and TNF and in dermal wound healing. J Immunol 2001: 166: 5749-5754.

41. Ferguson MW, O'Kane S. Scar-free healing: from embryonic mechanisms to adult therapeutic intervention. Philos Trans R Soc Lond B Biol Sci 2004: 359: 839-850.

42. Fries KM, Blieden T, Looney RJ, Sempowski GD, Silvera MR, Willis RA, Phipps RP. Evidence of fibroblast heterogeneity and the role of fibroblast subpopulations in fibrosis. Clin Immunol Immunopathol 1994: 72: 283-292.

43. Fries KM, Sempowski GD, Gaspari AA, Blieden T, Looney RJ, Phipps RP. CD40 expression by human fibroblasts. Clin Immunol Immunopathol 1995: 77: 42-51.

44. Fujisawa K, Miyamoto Y, Nagayama M. Basic fibroblast growth factor and epidermal growth factor reverse impaired ulcer healing of the rabbit oral mucosa. $J$ Oral Pathol Med 2003: 32: 358-366.

45. George J, Headen KV, Ogunleye AO, Perry GA, Wilwerding TM, Parrish LC, McVaney TP, Mattson JS, Cerutis DR. Lysophosphatidic acid signals through specific lysophosphatidic acid receptor subtypes to control key regenerative responses of human gingival and periodontal ligament fibroblasts. $J$ Periodontol 2009: 80: 1338-1347.

46. Ghani QP, Armitage GC, Hussain MZ. Biochemical alterations in inflammatory periodontal diseases I. Poly (ADP-ribose) synthetase activity in gingiva and gingival fibroblasts from humans with periodontitis. J Periodontal Res 1996: 31: 445-452.

47. Giannouli CC, Kletsas D. TGF-beta regulates differentially the proliferation of fetal and adult human skin fibroblasts via the activation of PKA and the autocrine action of FGF-2. Cell Signal 2006: 18: 1417-1429.

48. Glogauer M, Arora P, Yao G, Sokholov I, Ferrier J, McCulloch CA. Calcium ions and tyrosine phosphorylation interact coordinately with actin to regulate cytoprotective responses to stretching. J Cell Sci 1997: 110 ( Pt 1): 11-21.

49. Grinnell F. Fibroblasts, myofibroblasts, and wound contraction. J Cell Biol 1994: 124: 401-404.

50. Grinnell F. Fibroblast biology in three-dimensional collagen matrices. Trends Cell Biol 2003: 13: 264-269.

51. Grunheid T, Zentner A. Extracellular matrix synthesis, proliferation and death in mechanically stimulated human gingival fibroblasts in vitro. Clin Oral Investig 2005: 9: 124-130.

52. Guo F, Carter DE, Leask A. Mechanical tension increases CCN2/CTGF expression and proliferation in gingival fibroblasts via a TGFbeta-dependent mechanism. PLoS One 2011: 6: e19756.

53. Haase HR, Bartold PM. Enamel matrix derivative induces matrix synthesis by cultured human periodontal fibroblast cells. J Periodontol 2001: 72: 341-348.

54. Haase HR, Clarkson RW, Waters MJ, Bartold PM. Growth factor modulation of mitogenic responses and proteoglycan synthesis by human periodontal fibroblasts. $J$ Cell Physiol 1998: 174: 353-361.

55. Hakkinen $\mathrm{L}$, Larjava $\mathrm{H}$. Characterization of fibroblast clones from periodontal granulation tissue in vitro. J Dent Res 1992: 71: 1901-1907.

56. Hakkinen L, Westermarck J, Kahari VM, Larjava H. Human granulation-tissue fibroblasts show enhanced proteoglycan gene expression and altered response to TGF-beta 1. J Dent Res 1996: 75: 1767-1778.

57. Harley CB, Futcher AB, Greider CW. Telomeres shorten during ageing of human fibroblasts. Nature 1990: 345: 458-460. 
58. Hashimoto-Uoshima M, Noguchi K, Suzuki M, Murata A, Yanagishita M, Ishikawa I. Effects of interleukin-4 on proteoglycan accumulation in human gingival fibroblasts. $J$ Periodontal Res 2002: 37: 42-49.

59. Hill SJ, Ebersole JL. The effect of lipopolysaccharide on growth factor-induced mitogenesis in human gingival fibroblasts. J Periodontol 1996: 67: 1274-1280.

60. Hinz B, Celetta G, Tomasek JJ, Gabbiani G, Chaponnier C. Alpha-smooth muscle actin expression upregulates fibroblast contractile activity. Mol Biol Cell 2001: 12: 2730-2741.

61. Honardoust HA, Jiang G, Koivisto L, Wienke D, Isacke CM, Larjava H, Hakkinen L. Expression of Endo180 is spatially and temporally regulated during wound healing. Histopathology 2006: 49: 634-648.

62. Hou LT, Kollar EJ, Yaeger JA. Interactions between cloned gingival or periodontal ligament cells and oral epithelial cells in vitro. J Formos Med Assoc 1990: 89: 955964.

63. Hou LT, Liu CM, Wong MY. Expression of matrix proteins in cloned fibroblasts derived from periodontal tissue under different cell growth densities. Proc Natl Sci Counc Repub China B 1995: 19: 176-184.

64. Hwang IY, Son YO, Kim JH, Jeon YM, Kim JG, Lee CB, Park JS, Lee JC. Plasmaarc generated light inhibits proliferation and induces apoptosis of human gingival fibroblasts in a dose-dependent manner. Dent Mater 2008: 24: 1036-1042.

65. Hynes RO. Integrins: bidirectional, allosteric signaling machines. Cell 2002: 110: 673-687.

66. Hynes RO, Naba A. Overview of the Matrisome--An Inventory of Extracellular Matrix Constituents and Functions. Cold Spring Harb Perspect Biol 2011:

67. Irwin CR, Picardo M, Ellis I, Sloan P, Grey A, McGurk M, Schor SL. Inter- and intrasite heterogeneity in the expression of fetal-like phenotypic characteristics by gingival fibroblasts: potential significance for wound healing. J Cell Sci 1994: 107 ( Pt 5): 1333-1346.

68. Ivanovski S, Haase HR, Bartold PM. Isolation and characterization of fibroblasts derived from regenerating human periodontal defects. Arch Oral Biol 2001: 46: 679688.

69. Jeng JH, Lan WH, Wang JS, Chan CP, Ho YS, Lee PH, Wang YJ, Wang TM, Chen YJ, Chang MC. Signaling mechanism of thrombin-induced gingival fibroblastpopulated collagen gel contraction. Br J Pharmacol 2006: 147: 188-198.

70. Jeon YM, Kook SH, Son YO, Kim EM, Park SS, Kim JG, Lee JC. Role of MAPK in mechanical force-induced up-regulation of type I collagen and osteopontin in human gingival fibroblasts. Mol Cell Biochem 2009: 320: 45-52.

71. Kamata N, Fujimoto R, Tomonari M, Taki M, Nagayama M, Yasumoto S. Immortalization of human dental papilla, dental pulp, periodontal ligament cells and gingival fibroblasts by telomerase reverse transcriptase. J Oral Pathol Med 2004: 33: 417-423.

72. Kent LW, Rahemtulla F, Michalek SM. Interleukin (IL)-1 and Porphyromonas gingivalis lipopolysaccharide stimulation of IL-6 production by fibroblasts derived from healthy or periodontally diseased human gingival tissue. J Periodontol 1999: 70: 274-282.

73. Kim NY, Woo AM, Kim JR, Lee C. Exploration of senescence-associated genes by differential display reverse transcription polymerase chain reaction: prosaposin as a novel senescence-associated gene. Arch Pharm Res 2009: 32: 737-745.

74. Kimoto S, Matsuzawa M, Matsubara S, Komatsu T, Uchimura N, Kawase T, Saito S. Cytokine secretion of periodontal ligament fibroblasts derived from human deciduous teeth: effect of mechanical stress on the secretion of transforming growth factor-beta 1 and macrophage colony stimulating factor. J Periodontal Res 1999: 34: 235-243.

75. Klein T, Bischoff R. Physiology and pathophysiology of matrix metalloproteases. Amino Acids 2011: 41: 271-290. 
76. Kletsas D, Basdra EK, Papavassiliou AG. Effect of protein kinase inhibitors on the stretch-elicited c-Fos and c-Jun up-regulation in human PDL osteoblast-like cells. $J$ Cell Physiol 2002: 190: 313-321.

77. Konecny FA. Review of cellular and molecular pathways linking thrombosis and innate immune system during sepsis. J Res Med Sci 2011: 15: 348-358.

78. Kook SH, Son YO, Choe Y, Kim JH, Jeon YM, Heo JS, Kim JG, Lee JC. Mechanical force augments the anti-osteoclastogenic potential of human gingival fibroblasts in vitro. J Periodontal Res 2009: 44: 402-410.

79. Kook SH, Son YO, Hwang JM, Kim EM, Lee CB, Jeon YM, Kim JG, Lee JC. Mechanical force inhibits osteoclastogenic potential of human periodontal ligament fibroblasts through OPG production and ERK-mediated signaling. J Cell Biochem 2009: 106: 1010-1019.

80. Kylmaniemi M, Oikarinen A, Oikarinen K, Salo T. Effects of dexamethasone and cell proliferation on the expression of matrix metalloproteinases in human mucosal normal and malignant cells. J Dent Res 1996: 75: 919-926.

81. Lallier TE, Miner QW, Jr., Sonnier J, Spencer A. A simple cell motility assay demonstrates differential motility of human periodontal ligament fibroblasts, gingival fibroblasts, and pre-osteoblasts. Cell Tissue Res 2007: 328: 339-354.

82. Lapp CA, Lapp DF. Analysis of interleukin-activated human gingival fibroblasts: modulation of chemokine responses by female hormones. $J$ Periodontol 2005: 76 : 803-812.

83. Leivonen SK, Hakkinen L, Liu D, Kahari VM. Smad3 and extracellular signalregulated kinase $1 / 2$ coordinately mediate transforming growth factor-beta-induced expression of connective tissue growth factor in human fibroblasts. J Invest Dermatol 2005: 124: 1162-1169.

84. Li Y, Zheng W, Liu JS, Wang J, Yang P, Li ML, Zhao ZH. Expression of osteoclastogenesis inducers in a tissue model of periodontal ligament under compression. J Dent Res 2011: 90: 115-120.

85. Lim W, Lee S, Kim I, Chung M, Kim M, Lim H, Park J, Kim O, Choi H. The antiinflammatory mechanism of $635 \mathrm{~nm}$ light-emitting-diode irradiation compared with existing COX inhibitors. Lasers Surg Med 2007: 39: 614-621.

86. Lin RY, Sullivan KM, Argenta PA, Meuli M, Lorenz HP, Adzick NS. Exogenous transforming growth factor-beta amplifies its own expression and induces scar formation in a model of human fetal skin repair. Ann Surg 1995: 222: 146-154.

87. Lin Z, Sugai JV, Jin Q, Chandler LA, Giannobile WV. Platelet-derived growth factor-B gene delivery sustains gingival fibroblast signal transduction. J Periodontal Res 2008: 43: 440-449.

88. Lorimier S, Gillery P, Hornebeck W, Chastang F, Laurent-Maquin D, Bouthors S, Droulle $\mathrm{C}$, Potron $\mathrm{G}$, Maquart $\mathrm{FX}$. Tissue origin and extracellular matrix control neutral proteinase activity in human fibroblast three-dimensional cultures. $J$ Cell Physiol 1996: 168: 188-198.

89. MacNeil RL, D'Errico J, Strayhorn C, Pickrum H, Somerman MJ. Agents with periodontal regenerative potential regulate cell-mediated collagen lattice contraction in vitro. J Dent Res 1996: 75: 903-911.

90. Masella RS, Meister M. Current concepts in the biology of orthodontic tooth movement. Am J Orthod Dentofacial Orthop 2006: 129: 458-468.

91. McClain SA, Simon M, Jones E, Nandi A, Gailit JO, Tonnesen MG, Newman D, Clark RA. Mesenchymal cell activation is the rate-limiting step of granulation tissue induction. Am J Pathol 1996: 149: 1257-1270.

92. Meran S, Thomas DW, Stephens P, Enoch S, Martin J, Steadman R, Phillips AO. Hyaluronan facilitates transforming growth factor-beta1-mediated fibroblast proliferation. J Biol Chem 2008: 283: 6530-6545.

93. Michelet $\mathrm{H}$, Fontaniere B, Magloire H, Durand BM, Tabone E. Extracellular matrix and intermediate filaments in the first stages and repair of experimental gingivitis in man. J Biol Buccale 1991: 19: 329-341. 
94. Miller MD, Krangel MS. Biology and biochemistry of the chemokines: a family of chemotactic and inflammatory cytokines. Crit Rev Immunol 1992: 12: 17-46.

95. Modeer T, Yucel-Lindberg T, linuma M, Lerner UH, Andersson G. Epidermal growth factor potentiates interleukin 1 and tumor necrosis factor-induced prostaglandin biosynthesis in human gingival fibroblasts. Cytokine 1993: 5: 198-204.

96. Moolenaar WH. Development of our current understanding of bioactive lysophospholipids. Ann N Y Acad Sci 2000: 905: 1-10.

97. Morimoto T, Nishihira J, Kohgo T. Immunohistochemical localization of macrophage migration inhibitory factor (MIF) in human gingival tissue and its pathophysiological functions. Histochem Cell Biol 2003: 120: 293-298.

98. Mumford JH, Carnes DL, Cochran DL, Oates TW. The effects of platelet-derived growth factor-BB on periodontal cells in an in vitro wound model. $J$ Periodontol 2001: 72: 331-340.

99. Murata M, Hara K, Saku T. Dynamic distribution of basic fibroblast growth factor during epulis formation: an immunohistochemical study in an enhanced healing process of the gingiva. $J$ Oral Pathol Med 1997: 26: 224-232.

100. Murillo J, Wang Y, Xu X, Klebe RJ, Chen Z, Zardeneta G, Pal S, Mikhailova M, Steffensen B. Advanced glycation of type I collagen and fibronectin modifies periodontal cell behavior. J Periodontol 2008: 79: 2190-2199.

101. Nehls V, Hayen W. Are hyaluronan receptors involved in three-dimensional cell migration? Histol Histopathol 2000: 15: 629-636.

102. Nishijima Y, Yamaguchi M, Kojima T, Aihara N, Nakajima R, Kasai K. Levels of RANKL and OPG in gingival crevicular fluid during orthodontic tooth movement and effect of compression force on releases from periodontal ligament cells in vitro. Orthod Craniofac Res 2006: 9: 63-70.

103. Nishimura F, Terranova VP. Comparative study of the chemotactic responses of periodontal ligament cells and gingival fibroblasts to polypeptide growth factors. $J$ Dent Res 1996: 75: 986-992.

104. Nurden AT. Platelets, inflammation and tissue regeneration. Thromb Haemost 2011: 105 Suppl 1: S13-33.

105. Ogura N, Matsuda U, Tanaka F, Shibata Y, Takiguchi H, Abiko Y. In vitro senescence enhances IL-6 production in human gingival fibroblasts induced by lipopolysaccharide from Campylobacter rectus. Mech Ageing Dev 1996: 87: 47-59.

106. Ohnishi T, Daikuhara Y. Hepatocyte growth factor/scatter factor in development, inflammation and carcinogenesis: its expression and role in oral tissues. Arch Oral Biol 2003: 48: 797-804.

107. Okamura H, Yamaguchi M, Abiko Y. Enhancement of lipopolysaccharide-stimulated PGE2 and IL-1beta production in gingival fibroblast cells from old rats. Exp Gerontol 1999: 34: 379-392.

108. Okuda K, Kawase T, Momose M, Murata M, Saito Y, Suzuki H, Wolff LF, Yoshie H. Platelet-rich plasma contains high levels of platelet-derived growth factor and transforming growth factor-beta and modulates the proliferation of periodontally related cells in vitro. J Periodontol 2003: 74: 849-857.

109. Okuda K, Murata M, Sugimoto M, Saito Y, Kabasawa Y, Yoshie H, Saku T, Hara K. TGF-beta1 influences early gingival wound healing in rats: an immunohistochemical evaluation of stromal remodelling by extracellular matrix molecules and PCNA. J Oral Pathol Med 1998: 27: 463-469.

110. Oudhoff MJ, Blaauboer ME, Nazmi K, Scheres N, Bolscher JG, Veerman EC. The role of salivary histatin and the human cathelicidin LL-37 in wound healing and innate immunity. Biol Chem 2010: 391: 541-548.

111. Pender N, McCulloch CA. Quantitation of actin polymerization in two human fibroblast sub-types responding to mechanical stretching. J Cell Sci 1991: 100 ( Pt 1): 187-193.

112. Phipps RP, Borrello MA, Blieden TM. Fibroblast heterogeneity in the periodontium and other tissues. J Periodontal Res 1997: 32: 159-165. 
113. Pitaru S, McCulloch CA, Narayanan SA. Cellular origins and differentiation control mechanisms during periodontal development and wound healing. $J$ Periodontal Res 1994: 29: 81-94.

114. Pratsinis H, Giannouli CC, Zervolea I, Psarras S, Stathakos D, Kletsas D. Differential proliferative response of fetal and adult human skin fibroblasts to transforming growth factor-beta. Wound Repair Regen 2004: 12: 374-383.

115. Qwarnstrom EE, MacFarlane SA, Page RC, Dower SK. Interleukin 1 beta induces rapid phosphorylation and redistribution of talin: a possible mechanism for modulation of fibroblast focal adhesion. Proc Natl Acad Sci U S A 1991: 88: 12321236.

116. Qwarnstrom EE, Page RC. Development of a three-dimensional extracellular matrix synthesized by human diploid fibroblasts in vitro. J Cell Sci 1986: 84: 183-200.

117. Ray AK, Jones AC, Carnes DL, Cochran DL, Mellonig JT, Oates TW, Jr. Plateletderived growth factor-BB stimulated cell migration mediated through p38 signal transduction pathway in periodontal cells. J Periodontol 2003: 74: 1320-1328.

118. Redlich M, Roos H, Reichenberg E, Zaks B, Grosskop A, Bar Kana I, Pitaru S, Palmon A. The effect of centrifugal force on mRNA levels of collagenase, collagen type-I, tissue inhibitors of metalloproteinases and beta-actin in cultured human periodontal ligament fibroblasts. J Periodontal Res 2004: 39: 27-32.

119. Reti R, Kwon E, Qiu P, Wheater M, Sosne G. Thymosin beta4 is cytoprotective in human gingival fibroblasts. Eur J Oral Sci 2008: 116: 424-430.

120. Safavi SM, Kazemi B, Esmaeili M, Fallah A, Modarresi A, Mir M. Effects of low-level $\mathrm{He}-\mathrm{Ne}$ laser irradiation on the gene expression of IL-1beta, TNF-alpha, IFN-gamma, TGF-beta, bFGF, and PDGF in rat's gingiva. Lasers Med Sci 2008: 23: 331-335.

121. Sakai A, Ohshima M, Sugano N, Otsuka K, Ito K. Profiling the cytokines in gingival crevicular fluid using a cytokine antibody array. J Periodontol 2006: 77: 856-864.

122. Salo T, Makela M, Kylmaniemi M, Autio-Harmainen H, Larjava H. Expression of matrix metalloproteinase-2 and -9 during early human wound healing. Lab Invest 1994: 70: 176-182.

123. Sarasa-Renedo A, Tunc-Civelek V, Chiquet M. Role of RhoA/ROCK-dependent actin contractility in the induction of tenascin-C by cyclic tensile strain. Exp Cell Res 2006: 312: 1361-1370.

124. Schor SL, Ellis I, Irwin CR, Banyard J, Seneviratne K, Dolman C, Gilbert AD, Chisholm DM. Subpopulations of fetal-like gingival fibroblasts: characterisation and potential significance for wound healing and the progression of periodontal disease. Oral Dis 1996: 2: 155-166.

125. Sempowski GD, Chess PR, Moretti AJ, Padilla J, Phipps RP, Blieden TM. CD40 mediated activation of gingival and periodontal ligament fibroblasts. $J$ Periodontol 1997: 68: 284-292.

126. Shelton DN, Chang E, Whittier PS, Choi D, Funk WD. Microarray analysis of replicative senescence. Curr Biol 1999: 9: 939-945.

127. Simon MJ, Niehoff $P$, Kimmig B, Wiltfang J, Acil $Y$. Expression profile and synthesis of different collagen types I, II, III, and V of human gingival fibroblasts, osteoblasts, and SaOS-2 cells after bisphosphonate treatment. Clin Oral Investig 2010: 14: 51-58.

128. Singh $\mathrm{P}$, Carraher $\mathrm{C}$, Schwarzbauer JE. Assembly of fibronectin extracellular matrix. Annu Rev Cell Dev Biol 2010: 26: 397-419.

129. Smith PC, Caceres M, Martinez J. Induction of the myofibroblastic phenotype in human gingival fibroblasts by transforming growth factor-beta1: role of RhoA-ROCK and c-Jun N-terminal kinase signaling pathways. J Periodontal Res 2006: 41: 418425.

130. Smith PC, Santibanez JF, Morales JP, Martinez J. Epidermal growth factor stimulates urokinase-type plasminogen activator expression in human gingival fibroblasts. Possible modulation by genistein and curcumin. J Periodontal Res 2004: 39: 380-387. 
131. Smith RS, Smith TJ, Blieden TM, Phipps RP. Fibroblasts as sentinel cells. Synthesis of chemokines and regulation of inflammation. Am J Pathol 1997: 151: 317-322.

132. Soory M. Targets for steroid hormone mediated actions of periodontal pathogens, cytokines and therapeutic agents: some implications on tissue turnover in the periodontium. Curr Drug Targets 2000: 1: 309-325.

133. Spencer AY, Lallier TE. Mechanical tension alters semaphorin expression in the periodontium. J Periodontol 2009: 80: 1665-1673.

134. Stephens P, Davies KJ, al-Khateeb T, Shepherd JP, Thomas DW. A comparison of the ability of intra-oral and extra-oral fibroblasts to stimulate extracellular matrix reorganization in a model of wound contraction. J Dent Res 1996: 75: 1358-1364.

135. Stephens P, Davies KJ, Occleston N, Pleass RD, Kon C, Daniels J, Khaw PT, Thomas DW. Skin and oral fibroblasts exhibit phenotypic differences in extracellular matrix reorganization and matrix metalloproteinase activity. $\mathrm{Br} J$ Dermatol 2001: 144: 229-237.

136. Sukotjo C, Lin A, Song K, Ogawa T, Wu B, Nishimura I. Oral fibroblast expression of wound-inducible transcript 3.0 (wit3.0) accelerates the collagen gel contraction in vitro. J Biol Chem 2003: 278: 51527-51534.

137. Swamy SM, Tan P, Zhu YZ, Lu J, Achuth HN, Moochhala S. Role of phenytoin in wound healing: microarray analysis of early transcriptional responses in human dermal fibroblasts. Biochem Biophys Res Commun 2004: 314: 661-666.

138. Szpaderska AM, Walsh CG, Steinberg MJ, DiPietro LA. Distinct patterns of angiogenesis in oral and skin wounds. J Dent Res 2005: 84: 309-314.

139. Szpaderska AM, Zuckerman JD, DiPietro LA. Differential injury responses in oral mucosal and cutaneous wounds. J Dent Res 2003: 82: 621-626.

140. Takeuchi H, Kubota S, Murakashi E, Fukada T, Hashimoto S, Takigawa M, Numabe $Y$. Effect of transforming growth factor-beta1 on expression of the connective tissue growth factor (CCN2/CTGF) gene in normal human gingival fibroblasts and periodontal ligament cells. J Periodontal Res 2009: 44: 161-169.

141. Tamura M, Arakaki N, Tsubouchi H, Takada H, Daikuhara Y. Enhancement of human hepatocyte growth factor production by interleukin-1 alpha and -1 beta and tumor necrosis factor-alpha by fibroblasts in culture. J Biol Chem 1993: 268: 81408145.

142. Taoufik K, Mavrogonatou E, Eliades T, Papagiannoulis L, Eliades G, Kletsas D. Effect of blue light on the proliferation of human gingival fibroblasts. Dent Mater 2008: 24: 895-900.

143. Tipton DA, Dabbous MK. Autocrine transforming growth factor beta stimulation of extracellular matrix production by fibroblasts from fibrotic human gingiva. $J$ Periodontol 1998: 69: 609-619.

144. Tomofuji T, Ekuni D, Yamamoto T, Horiuchi M, Sakamoto T, Watanabe T. Optimum force and duration of toothbrushing to enhance gingival fibroblast proliferation and procollagen type I synthesis in dogs. J Periodontol 2003: 74: 630-634.

145. Tomofuji T, Sakamoto T, Ekuni D, Yamamoto T, Watanabe T. Location of proliferating gingival cells following toothbrushing stimulation. Oral Dis 2007: 13: 7781.

146. Toriseva MJ, Ala-aho R, Karvinen J, Baker AH, Marjomaki VS, Heino J, Kahari VM. Collagenase-3 (MMP-13) enhances remodeling of three-dimensional collagen and promotes survival of human skin fibroblasts. J Invest Dermatol 2007: 127: 49-59.

147. Trojanowska M. Role of PDGF in fibrotic diseases and systemic sclerosis. Rheumatology (Oxford) 2008: 47 Suppl 5: v2-4.

148. Trusolino L, Bertotti A, Comoglio PM. MET signalling: principles and functions in development, organ regeneration and cancer. Nat Rev Mol Cell Biol 2010: 11: 834848.

149. van der Pauw MT, Klein-Nulend J, van den Bos T, Burger EH, Everts V, Beertsen W. Response of periodontal ligament fibroblasts and gingival fibroblasts to pulsating fluid 
flow: nitric oxide and prostaglandin E2 release and expression of tissue non-specific alkaline phosphatase activity. J Periodontal Res 2000: 35: 335-343.

150. Verstappen J, Katsaros C, Torensma R, Von den Hoff JW. Bone marrow-derived cells in palatal wound healing. Oral Dis 2010: 16: 788-794.

151. Verstappen J, van Rheden RE, Katsaros C, Torensma R, Von den Hoff JW.

Preferential recruitment of bone marrow-derived cells to rat palatal wounds but not to skin wounds. Arch Oral Biol 2011:

152. Vij N, Sharma A, Thakkar M, Sinha S, Mohan RR. PDGF-driven proliferation, migration, and IL8 chemokine secretion in human corneal fibroblasts involve JAK2STAT3 signaling pathway. Mol Vis 2008: 14: 1020-1027.

153. Wrana JL, Sodek J, Ber RL, Bellows CG. The effects of platelet-derived transforming growth factor beta on normal human diploid gingival fibroblasts. Eur J Biochem 1986: 159: 69-76.

154. Wright HJ, Chapple IL, Matthews JB. TGF-beta isoforms and TGF-beta receptors in drug-induced and hereditary gingival overgrowth. J Oral Pathol Med 2001: 30: 281289.

155. Zhao XH, Laschinger C, Arora P, Szaszi K, Kapus A, McCulloch CA. Force activates smooth muscle alpha-actin promoter activity through the Rho signaling pathway. $J$ Cell Sci 2007: 120: 1801-1809. 


\section{Figure Legend}

Figure 1: Simplified scheme of the role of oral fibroblasts in wound healing. In response to injury, activated blood platelets release factors involved in thrombin activation, as well as lysophosphatidic acid (LPA) and several growth factors, such as platelet-derived growth factor (PDGF) and transforming growth factor- $\beta$ (TGF- $\beta$ ). Injury is accompanied by infection and the release of lipopolysaccharide (LPS) by bacteria. Thrombin, lysophosphatidic acid, platelet-derived growth factor, transforming growth factor- $\beta$ and lipopolysaccharide all act on resting fibroblasts via specific cell surface receptors, and thus trigger intracellular signals that promote fibroblast motility, contraction and proliferation. As an additional response, the wound fibroblasts start secreting chemokines such as interleukin-6 and interleukin-8 (IL-6, IL-8), which attract immune cells to the site of injury. Activated oral fibroblasts and immune cells interact directly via the receptors CD40 and CD40-ligand (CD40L) on their surface, and engage in a mutual paracrine crosstalk via secreted growth factors and cytokines. As a consequence, activated oral fibroblasts start to proliferate, secrete matrix metalloproteinases (MMPs) that digest damaged tissue, and release transforming growth factor- $\beta$, which in an autocrine fashion stimulates their own synthesis of new extracellular matrix (ECM). For more details, see text. 
Fig.1

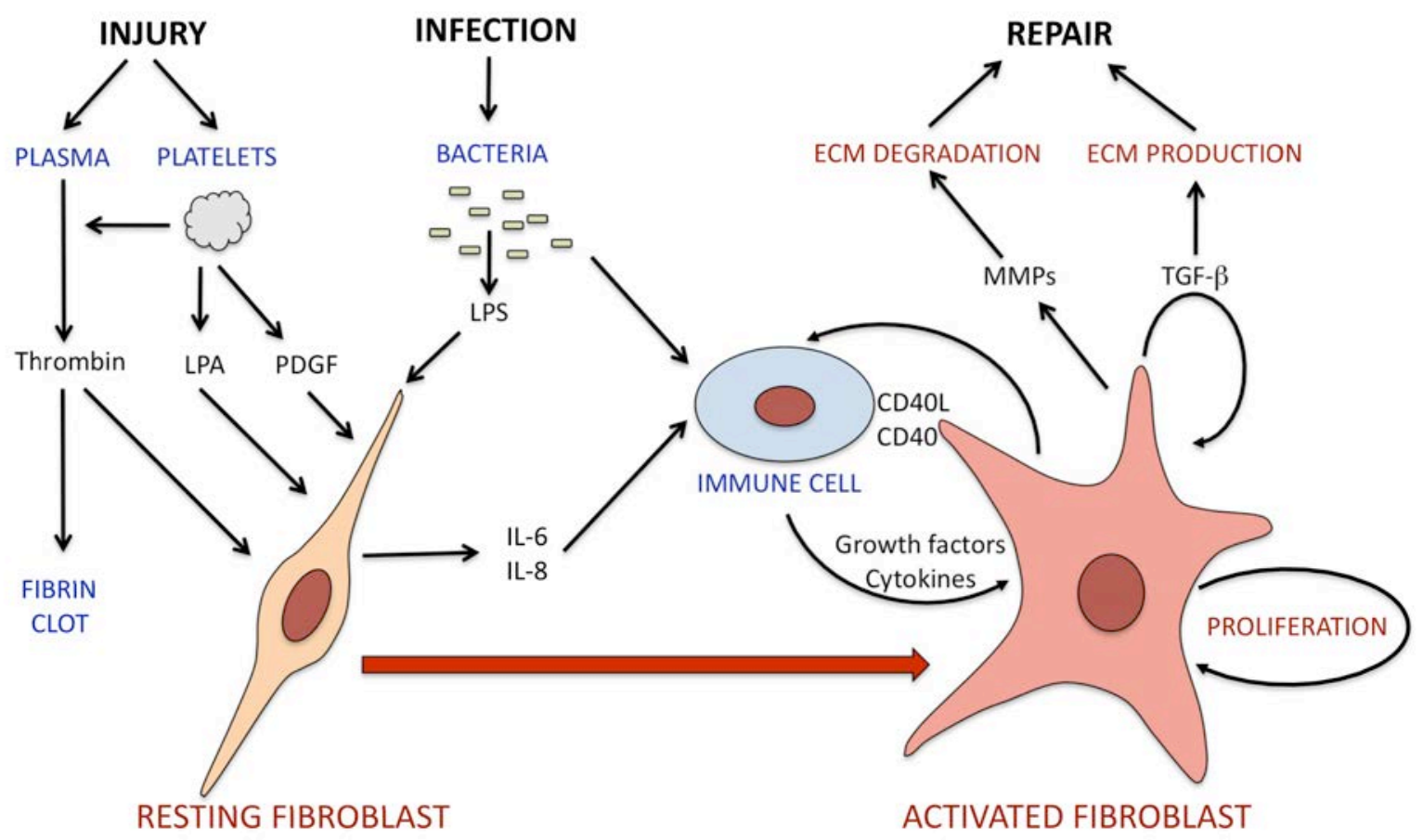

